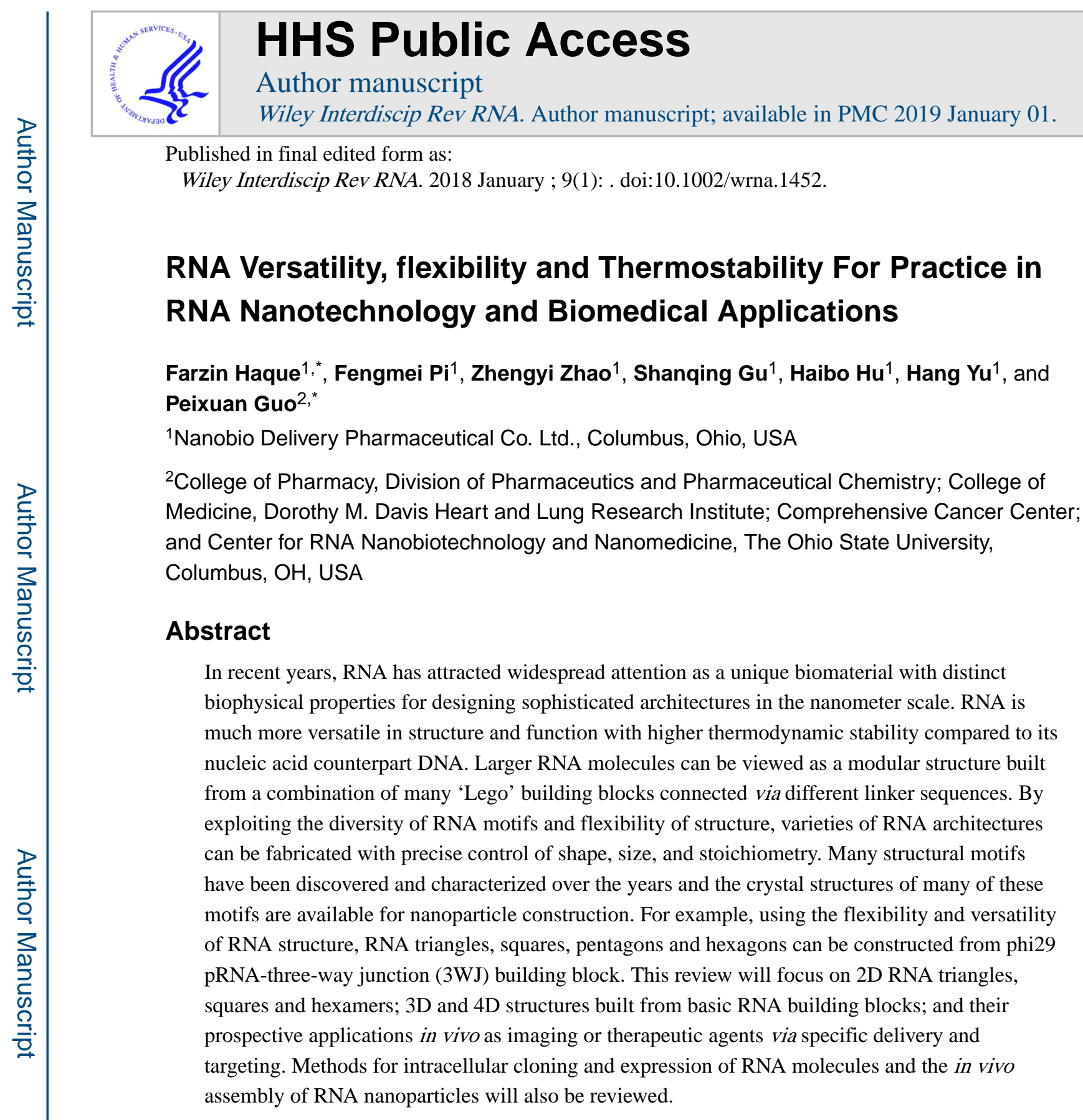

\title{
Graphical/Visual Abstract
}

\footnotetext{
*Address correspondence to: Peixuan Guo, Ph.D, Sylvan G. Frank Endowed Chair in Pharmaceutics and Drug Delivery, The Ohio State University, $460 \mathrm{~W} 12^{\text {th }}$ Avenue, Biomedical Research Tower (BRT) Room 912, Columbus, OH 43210, USA, Phone: 614-293-2114, guo.1091@osu.edu; Farzin Haque, Ph.D, Nanobio Delivery Pharmaceutical Co. Ltd., 1275 Kinnear Road, SciTech Campus OSU, Columbus, OH - 43212, Phone: 920-284-4749, fhaque@ nanobiousa.com.

The pRNA-3WJ is a thermodynamically stable motif, which was used to construct multiple structure 2D, 3D and 4D RNA nanostructures. The RNA triangle, square, hexamer, dendrimer, tetrahedron, and prism were constructed with pRNA-3WJ motif and discussed in this review. $11,47,50,88-90$

The pRNA-3WJ motif is an ideal scaffold to serve as a targeted drug delivery platform for clinical applications. RNA nanoparticles are negatively charged, which can reduce nonspecific binding to negatively charged cell membrane; they can be prepared by controlled synthesis with defined structure and stoichiometry; their multivalent nature provides a tool for combining therapy with targeting, delivery and detection functions. Targeted drug delivery could enhance therapeutic effects while minimizing side effects and toxicity. $11,22-27,41-46$
} 
The $3 \mathrm{WJ}$ motif derived from the packaging RNA of bacteriophage phi29 DNA packaging motor is highly thermodynamically stable. The $3 \mathrm{WJ}$ can be tuned to construct RNA triangles and squares. Through intermolecular interaction RNA hexamer can be constructed. The RNA triangular units can be further assembled into RNA 2D triangle, square, pentamer, hexamer, and arrays as well as 3D structures including tetrahedron, prism and dendrimers. The multi-functional RNA nanoparticles have shown enormous potential as delivery vehicles for targeted cancer therapy.

pRNA-3WJ Based RNA Nanotechnology

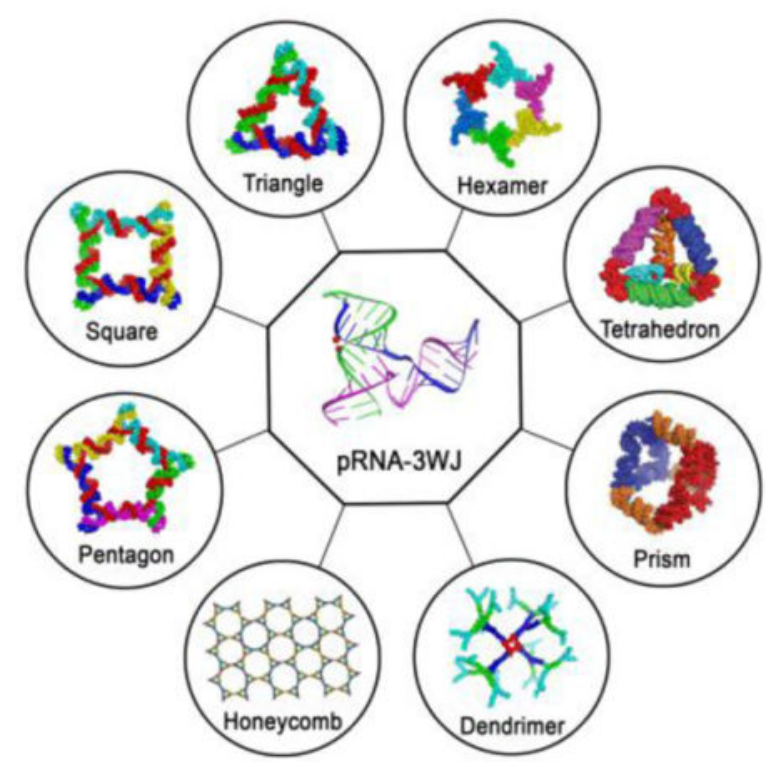

\section{Introduction}

A concept now widely accepted is that RNA is thermodynamically more stable than DNA and is much more versatile in structure and function compared to DNA, while in many cases display properties similar to proteins. Many secondary and tertiary structural RNA motifs have been revealed by biochemical, chemical and crystal analysis ${ }^{1,2}$. Several large structured RNA molecules such as, ribosomal RNA (rRNA) exist in nature, and these RNA complexes can be viewed as sophisticated architectures built from simple building blocks via modular assembly principles ${ }^{3}$. The diverse folding patterns lead to versatility in structure, which is necessary in order to interact with their specific substrates or targets, proteins, small ligands, DNA or other RNAs ${ }^{4}$. Genome sequencing revealed that only $1.5 \%$ of the human genomic dsDNA codes for proteins ${ }^{5}$. Subsequent evidence revealed that a substantial part of the rest 98.5\% (used to be called "Junk DNA") actually codes for small and, more recently, long noncoding $\mathrm{RNA}^{6}$. An increasing number of RNA molecules with new functions are being uncovered almost on a daily basis. Two significant hallmarks in drug development have been chemical drugs and protein-based drugs. A third milestone is projected to be RNA as drugs or drugs that target $\mathrm{RNA}^{7,8}$.

RNA nanotechnology involves bottom-up self-assembly of RNA nanoparticles in which the scaffold, targeting ligands, therapeutics agents, regulatory modules, and imaging agents can 
be exclusively made of RNA ${ }^{8-11}$. Varieties of RNA structural motifs such as three-way junction $(3 \mathrm{WJ})^{11,12}$, four-way junction $(4 \mathrm{WJ})^{13}$, kink-turn (helix-internal loop-helix motif with a $50^{\circ}$ bend in the helical axis) ${ }^{14}$, hairpins ${ }^{1}$, pseudoknot (at least two helices and two loops crossing the grooves of the helices) ${ }^{15}$, C-loops (where helical twists are increased in RNA helices) ${ }^{1}$, right-angle motifs (internal helical angle of $\left.90^{\circ}\right)^{16}$, tetraloop-receptors (hairpin motif interacting with a structured internal loop) ${ }^{17}$, paranemic motifs (crossover motif of stacked helices) ${ }^{18}$ and kissing loops ${ }^{19,20}$ have been investigated as scaffolds for constructing compact and stable RNA nanostructures with various shapes and sizes. RNA exhibits phenomenal structural flexibility exemplified by packaging RNA (pRNA) ${ }^{21}$ derived from bacteriophage phi29 DNA packaging motor. The pRNA has several structural features that can be used as a building block for constructing elegant 2D, 3D, and 4D architectures $11,19,22-27$. Many crystal structures of other RNA motifs are available and several motifs have been catalogued in databases $1,14,15,20,28,29$, such as RNAJunction and RNA 3D Motif Atlas from which one can extract detailed information such as, sequence, geometry, and function to rationally design new nanostructures with a high degree of control and predictability for desired applications.

In addition to structural diversity, RNA molecules exhibit diverse functions and immense potential for therapeutics development. RNA aptamers are an emerging class of targeting ligands, which function similar to protein antibodies by binding to their target with high affinity and specificity ${ }^{30,31}$. When integrating aptamers to RNA nanoparticles, they can guide the RNA nanoparticles to their target receptor molecule overexpressing regions and facilitate cell entry via receptor-mediated endocytosis ${ }^{31,32}$. Some aptamers can also function as inhibitor of signalling pathways ${ }^{33,34}$. Ribozymes are RNA molecules that can catalyze biochemical reactions ${ }^{35-37}$ and thereby serve as anti-viral and anti-cancer therapeutics.

Riboswitches are structured RNA molecules that can change their conformation in response to environmental stimuli ${ }^{35,38}$. Short interfering RNA (siRNA) and microRNA (miRNA) are short RNA fragments typically regulate post-transcriptional gene expression ${ }^{39,40}$. More noncoding RNAs are being discovered performing various regulatory roles in the cells. All these RNA-based modules have tremendous potentials to serve as novel drugs for disease treatment, but the bottleneck remains efficient delivery into specific diseased cells while minimizing damage to healthy cells and tissues. RNA nanotechnology has potential to overcome many of the challenges, as evidenced by series of publications showing that RNA nanoparticles display favourable attributes from a clinical translation perspective $9,22,24,25,41-46$ : homogenous and controllable in size and shape, which is important from manufacturing view-point; display tunable thermodynamic stability $25,26,47$, chemical stability (ex. use of $2^{\prime}$-Fluoro modified pyrimidines) $)^{11,48}$ and mechanical stability ${ }^{49}$, which is unique from a biomaterials physiochemical property standpoint; can be chemically synthesized at large scale and self-assembled with high efficiency from modular units harboring functionalities, which is necessary for quality control for pre-clinical and clinical trials; display favorable biodistribution and pharmacological profiles, which is essential for transitioning to clinic; and finally, composed exclusively of RNA, which can facilitate regulatory approval of the biomaterial for clinical use.

This review aims to highlight the versatility of some of the RNA motifs used for constructing programmable 2D RNA triangles, squares and hexamers as well as 3D RNA 
prisms, tetrahedrons and dendrimers. The structural features and design parameters are discussed in the context of RNA nanoparticle production. Finally, some of their applications in nanomedicine with an emphasis on in vivo biodistribution and therapeutic delivery studies are discussed to demonstrate the tremendous potentials of RNA nanotechnology platform in the nanomedicine frontier.

\section{TRIANGULAR RNA STRUCTURES CONSTRUCTED USING VARIOUS RNA MOTIFS}

\section{pRNA-3WJ based triangles}

The pRNA is a naturally occurring RNA structure. Each pRNA monomer contains a $3 \mathrm{WJ}$ motif, which is the central domain of pRNA and can be assembled from three short strands 'a' (18 nt), 'b' (20 nt) and 'c' (16 nt). The 3WJ (PDB ID: 4KZ2) $)^{50}$ is composed of three helices: $\mathrm{H} 1, \mathrm{H} 2$ and $\mathrm{H} 3$. Helices $\mathrm{H} 1$ and $\mathrm{H} 3$ are coaxially stacked aligned along a common axis forming $\sim 180^{\circ}$ angle. Helices $\mathrm{H} 1$ and $\mathrm{H} 2$ form a $60^{\circ}$ angle. Each helix can be extended by sticky ends and then linked together with a central common strand by hybridization to form a triangle ${ }^{26}$ (Fig. 1a). The final triangle contains four strands (three external and one internal) and has three $3 \mathrm{WJ}$ motifs at the vertices. The internal helical angles are all $60^{\circ}$. The smallest planar triangle is $\sim 12 \mathrm{~nm}$ in dimensions with 8-nt sticky ends that result in a $0^{\circ}$ dihedral angle between each $3 \mathrm{WJ}$ motifs. The entire construct is resistant to boiling temperature. Moreover, the vertices can be functionalized easily and then used for construction of supramolecular assemblies as well as delivery of therapeutic modules ${ }^{26}$.

\section{Kink-turn motif based triangles}

Kink-turn (k-turn) motifs are observed in dsRNA where a short bulge is followed by $\mathrm{G} \bullet \mathrm{A}$ and $\mathrm{A} \bullet \mathrm{G}$ base-pairs. A kink is generated with an internal angle of $50^{\circ}$ between the two helical axes. Lilley and colleagues developed a crystal lattice guided design of RNA nanoparticles using a double-k-turn motif, whereby two inverted k-turns (Kt-7; PDB: 4CS1) form a horse-shoe like structure by coaxial end-to-end stacking of the RNA helices ${ }^{51}$. The two loops are separated by 10 base pairs and lie on opposite strands with a two-fold rotational axis. Three two-k-turn units can associate to form a triangle with three-fold rotational symmetry (Fig. 1b). The triangle can also be formed in presence of L7Ae proteins that drive the folding of k-turns ${ }^{51}$ (Fig. 1c). Similarly, Saito's group used the box C/D k-turn RNA and ribosomal protein L7Ae to generate synthetic equilateral shaped RNA-protein complex ${ }^{52}$. The proteins facilitate the formation of triangles by stabilizing the k-turn regions with $60^{\circ}$ between the helices. The results demonstrate how versatile k-turn motifs are in nature for organizing long-range architectures and mediating tertiary contacts. Furthermore, RNA-protein complexes provide a new avenue of inducing structural changes (mimicking ribosomes) and for organizing proteins into larger machineries for nanotechnological applications.

\section{Seneca Valley Virus (SVV)-Internal Ribosome Entry Site (IRES) RNA motif based triangles}

Hermann and colleagues developed a crystal structure guided principle for self-assembling RNA nano-triangles ${ }^{53}$. The corner motifs were extracted from ligand-responsive RNA 
switch motifs located in subdomain IIa of IRES elements of SVV (Fig. 1d). The triangle is composed of three symmetrical identical corner motifs, each forming an inner and outer strand harboring 4-nt sticky end that base-pairs with neighboring corner strands. The overall structure is twisted to accommodate the $90^{\circ}$ corner motifs. The edge lengths can be increased to form larger triangles. The 12 termini of the 6 short single strands are located on one face of the triangle and this arrangement offers opportunities for constructing complex shapes as well as functionalization for sensors and nanotechnology applications. Since the motifs are ligand-dependent switches, conformational changes can be also induced to tune the biophysical properties of the triangle.

\section{Tetra-U helix based triangles}

Khisamutdinov and colleagues used a computational approach to design an artificial $3 \mathrm{WJ}$ structure consisting of three dsRNA helices connected with a bulge of $4 \times 4 \times 4$ single-stranded $\mathrm{Us}^{54}$ (Fig. 1e). The four Us provide greater flexibility for assembly of higher-ordered structures. Planar equilateral triangular geometries can be formed with the core $3 \mathrm{WJ}$ scaffold at the vertices which are connected by 22 bp duplexes ( 2 complete RNA turns). The triangles can be functionalized with imaging dyes and siRNA.

\section{Thermus thermophiles 16S rRNA based triangles}

Shapiro and colleagues searched through RNAJunction database ${ }^{20}$ using NanoTille ${ }^{55}$ software and identified a $3 \mathrm{WJ}$ motif from 16S rRNA that has an intrinsic interhelical angle of $\sim 60^{\circ}$, and two interhelical angles of $\sim 150^{\circ 15}$ (Fig. 1f). Triangular shaped RNA nanoparticle was then generated with the $3 \mathrm{WJ}$ at each vertex and assembled from four strands.

\section{Hand-in-hand (loop-loop) interactions to produce RNA trimers}

Phi29 pRNA contains two domains: a helical domain located at the paired $5^{\prime}$ - and $3^{\prime}$ - ends ${ }^{58}$ and an interlocking domain located at the central part of the pRNA structure that binds the connector ${ }^{58-61}$. The central domain of each pRNA subunit contains a right-hand loop and a left-hand loop, that can be re-engineered as needed to form higher order complexes. The right-hand loop is denoted with an uppercase letter (ex. A) and the left loop with a lowercase letter with a prime (ex. $\left.a^{\prime}\right)$. When the two loops interact by complementation, a same letter pair with upper and lower cases respectively, is assigned. For instance, when pRNA A- $b^{\prime}$ is mixed with pRNA B-e' plus pRNA E-a', hand-in-hand interactions will produce a trimer with $\mathrm{A}$ interacting with $\mathrm{A}^{\prime}$, B interacting with $\mathrm{b}^{\prime}$ and $\mathrm{E}$ interacting with $\mathrm{e}^{\prime}$ (Fig. 1g).

\section{RNA SQUARE NANOSTRUCTURES CONSTRUCTED USING VERSATILE RNA MOTIFS \\ pRNA-3WJ based squares}

The pRNA-3WJ (PDB ID: 4KZ2) ${ }^{50}$ scaffold is highly versatile. To form nanostructure with a square geometry, the native pRNA-3WJ internal angle of $60^{\circ}$ can be stretched to $90^{\circ 25}$. The final square consists of five strands (four short external strands and one complementary long internal strand) (Fig. 2a). The resulting nanoparticle contains a $3 \mathrm{WJ}$ at each vertex and 
A-type duplex RNA along each edge. The linking sequences can be shortened or extended to create squares with tunable sizes. Additional RNA sequences or motifs can be placed at each vertex for desired functionalities.

\section{Kink-turn motif based square}

Lilley and colleagues used the same double k-turn motif (Kt-7; PDB: 4CS1) described earlier to form a square shaped geometry through coaxial end-to-end interactions ${ }^{51}$ (Fig. 2b). A four-fold axis of rotational symmetry is observed through the center of the square. As seen in triangles, the square-shaped structure can also be formed in presence of L7Ae proteins.

\section{Tetra-U helix based squares}

The tetra-U helix described earlier is a highly flexible module and can be used a building block to build square geometries by stretching the intra-helical angle to $90^{\circ 54}$ (Fig. 2c). The formation of a homogenous RNA band in native PAGE demonstrated that the square is stable. Furthermore, DNA/RNA hybrids can be formed to fine-tune the physiochemical properties of the complexes for controlled release of cargoes.

\section{rRNA derived from bacterial ribosome}

Following is an example of building a nanostructure using information available in database. Nanotiler is a software developed by Shapiro and colleagues to build RNA nanostructures ${ }^{55}$. One of its algorithm is a JunctionScanner than can scan through RNA Junction database 20 and extract structural elements, like a $3 \mathrm{WJ}$ derived from large ribosomal unit of Deinococcus radiodurans (PDB: 2OGM) ${ }^{63}$. The core junction consists of three strands of length $4 \mathrm{nt}, 5 \mathrm{nt}$ and $7 \mathrm{nt}$ forming approximately a $90^{\circ}$ between the helical axes (Fig. 2d). In the final square configuration, the sides of the square are $47 \mathrm{nt}$ in length, while the core strand in $58 \mathrm{nt}$ in length. Each strand forms an intermolecular interaction with the other component strands.

\section{$90^{\circ}$ RNA motifs derived from cellular translational machineries to generate squares}

Jaeger and colleagues used three topologically different $90^{\circ}$ motifs exhibiting different thermodynamic, kinetic and folding properties to construct RNA squares ${ }^{16}$ (Fig. 2e). The first is the RA-motif, a highly prevalent structure in rRNAs. It forms a L-shaped structure by packing two helical stems along their shallow-groove through ribose-zipper interactions. The second is the $3 \mathrm{WJ}$ motif derived from $23 \mathrm{~S}$ rRNA in Haloarcula marismortui. It forms a Tshaped structure, where two helices are co-axially stacked and the third helix protrudes out at $90^{\circ}$. The third is the tRNA-motif derived from tRNA(qSer), hybrid class I/class II tRNA, which consists of 4- or 5-way junctions that form a L-shaped structure. The individual motifs have two kissing loops at two helical branches and these form loop-loop interactions with three other monomeric units to generate square shaped structures.

\section{Hepatitis C virus (HCV) - Internal Ribosome Entry Site (IRES) RNA motif}

Herman and colleagues used the $90^{\circ}$ bend in the domain IIa bulge in the IRES of HCV genome to generate a double-stranded RNA square ${ }^{62}$ (Fig. 2f). Molecular modelling revealed that a $100 \mathrm{nt}$ square can be self-assembled from four copies of two distinct strands, an inner strand of $10 \mathrm{nt}$ and an outer strand of $15 \mathrm{nt}$. Each strand needs a four-base single 
stranded sticky-end for complementary hybridization. The square was assembled, crystallized and the final structure solved at $2.2 \AA$ resolution. The sides of the square are $\sim 6$ $\mathrm{nm}$ and the inner cavity was $\sim 1.8 \mathrm{~nm}$. The results demonstrate the feasibility of sequencedependent programmed self-assembly of structured RNA nanoparticles.

\section{RNA HEXAMER NANOSTRUCTURE CONSTRUCTED USING VERSATILE RNA MOTIFS}

\section{Hexameric pRNA ring produced by hand-in-hand interaction of reengineered right and left- hand loops}

In nature, the pRNA from bacteriophage phi29 DNA packing motor forms a hexameric ring to gear the motor via hand-in-hand or loop-loop interactions ${ }^{21,64,65,87}$. The 4-nt loop sequences of the individual monomers can be engineered to form dimer, trimer, and hexamer nanoparticles by bottom-up self-assembly of re-engineered RNA fragments ${ }^{64,65}$. However, the resulting constructs are not thermodynamically stable for in vivo applications. Stable interlocking loops can be generated by extending the native 4-nt to 7-nt complementary loop sequences ${ }^{19,66}$ (Fig. 3a). The resulting constructs can be further functionalized with desired functional modules for desired applications ${ }^{19,67}$. In this approach, all functionalities can be pre-designed in the primary sequence and then assembled, thus ensuring the production of homogeneous nanoparticles.

\section{Hexamer nanorings based on RNAI/lli kissing complexes}

Shapiro, Jeager and colleagues used a strategy based on the principle of RNA architectonics ${ }^{68,69}$, whereby ssRNAs harboring partially folded structural motifs form monomers followed by bottom-up assembly into nanocomplexes utilizing tertiary hydrogen bond formations. Hexamers based on the geometry of the RNAI/IIi kissing-loop complex can be assembled using two approaches ${ }^{70,71}$. Two analogous RNA monomers, each with a single loop sequence on either end of the central helix, can self-assemble through specific complementary kissing-loop interactions (Fig. 3b). Alternatively, a single monomer designed with both complementary loop sequences can self-assemble with other monomers. However, for complete control over assembly, six specific kissing-loop interactions are required and these monomers need to assemble selectively in concert. Accordingly, six distinct 7-nt sequences were designed computationally and assembled into hexameric rings with high yield ${ }^{70}$. These hexameric rings can be further generated co-transcriptionally in one pot, and also can be functionalized with siRNAs capable of being processed by Dicer ${ }^{71}$.

\section{Hexamers formed by sticky end linkage of pRNA-3WJ triangles}

The pRNA-3WJ triangles can be functionalized at the vertices with specific sticky ends. A triangular monomer unit is constructed with 6-nt sticky ends denoted A, b' and C. When mixed in 1:1 ratio with another triangular monomer with 6-nt sticky ends denoted a', b' and $c^{\prime}$, thermostable hexamers can be generated through sticky-end complementary binding of A-a' and C-c'26 (Fig. 3c). The b' corner ends remains open, if needed, for post-assembly functionalization with desired module, such as siRNA. 


\section{RNA 3D NANOSTRUCTURES CONSTRUCTED USING VERSATILE RNA MOTIFS}

3D RNA nanostructures are particularly attractive for encapsulating drugs, imaging modules and other functionalities for not only shielding the functional modules from in vivo cellular environment, but also for controlled release of the modules at the specific site.

\section{pRNA-based nanocages}

Guo and colleagues designed tetrahedrons ${ }^{72}$ (Fig. 4a) and triangular nanoprisims ${ }^{73}$ (Fig. 4b) utilizing the pRNA-3WJ as a building block. First, triangular structures were assembled with a $3 \mathrm{WJ}$ motif at the vertices, which were then joined by duplexes. A $21 \mathrm{nt}$ single-stranded RNA linker was then added to each vertex to link two triangles face-to-face through complementary hybridization. For added flexibility to generate the $90^{\circ}$ bend, four Us were added between the linker sequence and core $3 \mathrm{WJ}$ sequence. The entire construct assembles from eight strands and displays a size of $\sim 11 \mathrm{~nm}$. The size is tunable by simply increasing or decreasing the sides of the prism by one helical turn. The nanoprism can encapsulate therapeutic cargoes and also harbor functionalities at the vertices.

In a different approach, Mao and colleagues designed RNA nanoprsims using pRNA monomers as building blocks ${ }^{74}$. Two approaches, one relying on loop-loop interactions and the other on palindrome sequence mediated sticky-end hybridization was used. Triangular prisms were designed using three pRNA monomers with three different loop sequences (ab', b-c', c-a') (Fig. 4c) and a four-base palindrome sequence at the 3'-end. Upon annealing, the three complementary loop sequences hybridize ( $\mathrm{a} / \mathrm{a}^{\prime} ; \mathrm{b} / \mathrm{b}^{\prime}$ and $\left.\mathrm{c} / \mathrm{c}^{\prime}\right)$ via loop-loop interactions to form a closed triangle while the sticky ends at the 3 '-ends link to each other to connect the triangular faces. Similarly, using the same design principles, a tetragonal prism can be constructed from four pRNA monomers (a-b', b-c', c-d', and d-a') with a fourbase palindrome sequence at the 3 '-end (Fig. 4d).

\section{Transfer RNA (tRNA) polyhedrons}

Jaeger and colleagues used tRNA as a structural motif and spatial addressability feature to design well defined 3D polyhedral structures ${ }^{75}$. Class II tRNAs, such as tRNA(Ser) has a 5way helix junction with three arms extending in the $\mathrm{x}-, \mathrm{y}$ - and $\mathrm{z}$-dimensions making angles of $120^{\circ} 70^{\circ}$ and $25^{\circ}$, respectively. By employing an inverse folding design strategy, tRNA(Ser) motif can be used to generate a square geometry through loop-loop interactions. Upon addition of a single-stranded sticky-end, two-squares can be connected through four sets of tail-tail interactions to generate a non-uniform square anti-prism (Fig. 4e). Due to the structural constraints imposed by tRNA motif, the squares are twisted $30^{\circ}$ relative to each other, and thus the eight triangular sides are non-equilateral. As proof-of-concept, the tRNA motifs can be functionalized with biotin in order to conjugate streptavidin protein, thereby demonstrating its potential to organize molecules with high precision and as a potential carrier of drugs. 


\section{RNA cubes designed in silico}

In contrast to aforementioned use of known structural elements with pre-folded RNAs, Shapiro and colleagues designed a 3D RNA cube computationally from short strands and then experimentally validated the designs ${ }^{76}$. The cubes are $\sim 13 \mathrm{~nm}$ long, composed of 6 core strands or 10 oligos with single stranded corner linkers amenable for functionalization (Fig. 4f). The cubes can be self-assembled in one pot co-transcriptionally. The thermal stabilities can be fine-tuned by altering the composition of strands with DNA (low $\mathrm{T}_{\mathrm{m}}$ ) or 2'-F (high $\mathrm{T}_{\mathrm{m}}$ ). The kinetics of association and tunable thermal and chemical stabilities can be used for conditional activation of multiple functionalities to modulate biological pathways ${ }^{77}$.

\section{Nanoprisms}

Mao and colleagues designed RNA tiles that can self-assemble into a homo-octameric cube $^{78}$. The RNA tile consists of two strands and contains three helical regions, two internal single-stranded loops and two single stranded tails (Fig. 4g). Three structural features are utilized in the design of the prism structure: a T-shaped junction (artificial), a $90^{\circ}$ bend (derived from RNA element in HCV) and sticky-end hybridization. The tiles form homotetramers via T-junctions and the squares further homo-dimerize through sticky end cohesion to generate homo-octameric prisms in a cooperative assembly process.

\section{RNA dendrimers}

Dendrimers are particularly attractive for delivering multiple types of therapeutics, but several challenges remain for conventional chemical building units: (1) Scaffold assembly involves multistep chemical synthesis and purification which leads to low yield and structural defects for anything bigger than G2 dendrimers; (2) Site-specific functionalization for introducing diverse payloads is extremely challenging requiring several protection and de-protection steps; (3) Current platforms often lack targeting capabilities and rely mainly on EPR effects for tumor delivery; some use protein-based targeting ligands, which in turn, can induce immunogenicity; (4) Organic dendrimers require additional steps, such as crosslinking followed by PEGylation to increase their stability, and reduce cytotoxicity; (5) Organic dendrimers rely on their cationic nature to bind anionic RNAi and thus have difficulty in reaching a homogenous state important for drug quality control as well as in vivo toxicity. (6) Organic dendrimers generally suffer from low water-solubility and high aggregation propensity. Recently Guo and colleagues used pRNA-3WJ as a scaffold to construct G0-G4 RNA dendrimers with precise control of size (20-50 nm), shape (3D globular) and stoichiometry (3-32 functionalities) ${ }^{27}$ (Fig. 4h, i). RNA dendrimers harboring imaging, targeting and therapeutic modules can be assembled with high efficiency by mixing the component strands in equimolar ratio. RNA dendrimers exhibit elasticity, which will facilitate trafficking across narrow cavities, as well as processing of RNAi. Compared to other polymers, the degradation of RNA can be timely controlled by adjusting the percent and location of 2'-F nucleotides. RNA dendrimers also retain all the favourable thermodynamic and pharmacological traits of the pRNA-3WJ. 


\section{APPLYING THE FLEXIBILITY AND VERSITILITY OF RNA PROPERTY FOR CONSTRUCTING RNA TRIANGLE, SQUARE, PENTAGON BY TUNING INTERIOR RNA 3WJ ANGLE FROM $60^{\circ}$ TO $90^{\circ}$ OR $108^{\circ}$}

A simple method for the design and synthesis of RNA triangle, square, and pentagon have been developed by stretching RNA $3 \mathrm{WJ}$ native angle from $60^{\circ}$ to $90^{\circ}$ and $108^{\circ}$, using the $3 \mathrm{WJ}$ of the pRNA from bacteriophage phi29 dsDNA packaging motor ${ }^{56}$ (Fig. 5). This method for the construction of elegant polygons can be applied to other RNA building blocks including RNA 4-way, 5-way, and other multi-way junctions to construct higher order 3D structures with controllable size, shape and geometry.

\section{DIVERSE RNA NANOSTRUCTURES WITH DISEASED CELL TARGETING AND THERAPEUTIC DELIVERY EFFECTS}

RNA nanoparticles can be developed into targeted drug delivery systems. RNA based therapeutics (such as siRNA or miRNA) and targeting ligands (such as, aptamers) can be simply incorporated to the RNA nanoparticle scaffold by fusing the sequences. Chemical based ligands (such as, folate or galactose) or chemotherapeutic drugs can be conjugated to the terminal ends of the helices using standard conjugation methods. RNA nanoparticles can be delivered locally, as exemplified by ocular delivery and intra-tumoral delivery or more commonly through systemic injection, as discussed in detail below. By controlling the size, shape and physiochemical properties of RNA nanoparticles, the pharmacological profiles in vivo can be tuned to achieve optimal targeting and therapeutic efficacy.

\section{Ocular delivery of RNA nanoparticles}

$\mathrm{Li}$ and colleagues demonstrated that delivery of RNA nanoparticles to different ocular tissues (conjunctiva, cornea, retina, and sclera) is size and shape dependent ${ }^{79}$. Following non-invasive subconjunctival injection, ocular biodistribution was investigated for pRNA-3WJ (three-branched structure) and pRNA-X (four-branched structure extended from pRNA-3WJ) nanoparticles, which are similar in size, but different in shape. The RNA nanoparticles were distributed from the injection site to different ocular tissues and then cleared from the eyes rapidly via the lymph duct. Significant internalization of both the pRNA-3WJ and pRNA-X nanoparticles were observed in conjunctiva and cornea cells, but only the pRNA-X was able to penetrate the retina cells (Fig. 6a).

\section{Systemic delivery of siRNA to treat gastric cancer and breast cancer}

Therapeutic pRNA-3WJ nanoparticles were constructed harboring with Folate as a targeting ligand, Alexa-647 as an imaging module and an siRNA targeting BRCAA1 (breast cancerassociated antigen 1) that is over-expressed in gastric cancer. Upon systemic injection, RNA nanoparticles targeted subcutaneous MGC803 xenografts with little or no accumulation in healthy vital organs and tissues (Fig. 6b). The RNA nanoparticles were internalized into the cells via Folate receptor mediated endocytosis. The double-stranded BRCAA1 siRNA region is processed by RISC complex in the cytoplasm resulting in silencing of BRCAA1 gene and subsequent down-regulation of Bcl-2 gene, and further up-regulation of $\mathrm{Rb}$ and $\mathrm{Bax}$ gene, 
inducing cell apoptosis and inhibiting tumor growth ${ }^{46}$. Similaly, Zhang and colleagues used pRNA-3WJ based nanoparticles to tackle tamoxifen-resistant breast cancer ${ }^{43}$. They constructed pRNA-3WJ-HER2apt (HER2 targeting RNA aptamer)-siMED1 (ER coactivator Mediator Subunit 1) nanoparticle to deliver siRNA to HER2-overexpressing human breast cancer cells. Upon cellular internalization via HER2 aptamer, the siRNA reduced MED1 expression, and significantly decreased ERa-mediated gene transcription. Following i.v. treatment in an orthotopic xenograft model, tumor growth and metastasis were inhibited and the cancer cells become sensitized to tamoxifen (Fig. 6c). In addition, RNA nanoparticles also reduced the cancer stem cell content of breast tumors when combined with tamoxifen treatment in vivo. In a more challenging orthotopic glioblastoma mouse model, pRNA-3WJ nanoparticles harboring folate as a targeting ligand and luciferase siRNA was able to target glioblasoma cells specifically and knockdown luciferase expression after systemic injection ${ }^{80}$ (Fig. 6d). The results highlight the potential to treat glioblastoma using RNA nanoparticles.

\section{Systemic delivery of anti-miRNA to treat breast, prostate and brain cancer}

Targeted delivery of anti-miRNA to knock-down oncogenic miRNA is exemplified by the pRNA-3WJ nanoparticles in three different tumor models. As anti-miRNA module, an 8mer Locked Nucleic Acid (LNA, conformationally restricted nucleotide analogs) was fused to the pRNA-3WJ scaffold. LNAs are resistant to nucleases and upon binding to their complementary miRNA seed region ${ }^{82}$ with very high affinity and specificity, they can trigger miRNA inhibition in a dose dependent manner. In an orthotopic Triple Negative Breast Cancer model, pRNA-3WJ nanoparticles harboring EGFR targeting RNA aptamers and anti-miR-21 suppressed tumor growth efficiently without collateral damage to healthy cells $^{24}$ (Fig. 6e). In a similar manner, pRNA-3WJ nanoparticles were administered systemically to a subcutaneous prostate tumor xenograft bearing mice, pRNA-3WJ nanoparticle harboring PSMA targeting RNA aptamers could deliver anti-miR-21 or antimiR-17 to inhibit tumor growth at low doses (Fig. 6f). More impressively, in an orthotopic patient-derived glioblastoma model, cancer cell apoptosis and tumor growth regression were observed after systemic injection of pRNA-3WJ/Folate/anti-miR-21 nanoparticles ${ }^{44}$. The specific knock-down of miR-21 in the aforementioned tumor models were validated by assaying the downstream target genes by RT-PCR at mRNA levels and Western blot at the protein levels.

\section{Local delivery of siRNA using hexameric RNA nanoring}

Hexameric RNA nanorings can be functionalized with 6 double-stranded siRNAs (ex. siGFP) at the $\operatorname{arms}^{83}$. Athymic nude mice were subcutaneously grafted with MDA-MB-231 cells stably expressing GFP. For in vivo delivery, the nanorings were associated with bolaamphiphilic cationic carriers and injected intratumorally. The silencing of GFP gene was analyzed by measuring the fluorescent intensities in treated vs control tumors ex vivo. A $\sim 90 \%$ decrease in GFP fluorescence intensity was observed for the nanorings indicating that the nanorings can be efficiently processed by Dicer to release the siRNA and trigger gene knockdown.

Wiley Interdiscip Rev RNA. Author manuscript; available in PMC 2019 January 01. 


\section{RNA nanostructures for immunotherapy}

The immune responses of RNA nanoparticles is tunable and depends on the sequence, size and shape of the RNA nanoparticle. The pRNA-based nanoparticles by themselves do not induce release of pro-inflammatory cytokines and interferons in nature, which is an attractive feature of a therapeutic delivery vector. Upon incorporating $\mathrm{CpG}$ (short sequences containing unmethylated $\mathrm{C}$ and $\mathrm{G}$ nucleotides) DNA motifs, pRNA nanoparticles can become highly immuno-stimulatory. In both pRNA-polygons ${ }^{56}$ and pRNA nanoprisms ${ }^{73}$ fused CpG DNA induced strong induction of TNF- $a$ and IL-6 depending on the shape of polygons and number of $\mathrm{CpG}$ per nanoparticle, compared to $\mathrm{CpG}$ alone (Fig. $6 \mathrm{~g}$ ). The results demonstrate the potentials of RNA nanoparticles to serve as vaccine adjuvant and as an immunotherapeutic reagent.

\section{RNA nanostructures for chemotherapy}

Chemical drugs remain the first line of treatment for cancer. Various nanodrug delivery systems have been explored to reduce its systemic toxicity during treatment. Compared to traditional lipid vesicle based nano-delivery systems, RNA nanoparticles have a great advantage of sub-nanometer scale size controllability, and thus greatly reduce nonspecific accumulation of drugs in liver and lung, to eventually reduce its side effect. Annexin A2pRNA-3WJ nanoparticles harboring ovarian cancer targeting aptamer can specifically target ovarian cancer xenograft tumor in mice after tail vein injection and showed great potential for targeted doxorubicin delivery with enhanced efficacy ${ }^{81}$ (Fig. 6h).

\section{Cloning and expression of RNA molecules and assembly of RNA nanoparticles in the cell or in vivo}

Cloning and expression of proteins in the cell or in the body have been investigated extensively for many decades. However, there are limited information regarding cloning and expression of RNA molecules in the cell or in vivo. The unusual modularity of phi29 motor pRNA made it possible to fabricate and assemble functional RNA nanoparticles including dimers, trimers, tetramers and hexamers in vitro or in the cell via hand-in-hand interactions by bottom up self-assembly ${ }^{64}$. The thermostable transfer RNA (tRNA) motif has been used as a scaffold to escort and express varieties of small RNA motifs, including phi29 pRNA, Sephadex aptamer and Streptavidin aptamer ${ }^{84,85}$.

Instability after expession in the cell and misfolding resulting in loss of function are frequently encountered during constructing of fusion RNA complexes due to changes in energy landscapes and the nearest-neighbour principles. The pRNA-3WJ motif (Fig. 1a) exhibits unusually robust properties as a scaffold with a low folding energy ${ }^{11,47}$. It can be assembled from three pieces of RNA strands resulting in a structure with high thermodynamic stability, can assemble with high efficiency even in the absence of metal salts, is resistance to denaturation even in the presence of $8 \mathrm{M}$ urea, and does not dissociate at ultra-low concentrations ${ }^{11,50}$. The motif can provide a leading core and drive the correct folding of other functional RNA molecules fused to the RNA complex with controllable and predictable outcome ${ }^{86}$. The three component strands of $3 \mathrm{WJ}$ motif can be cloned into DNA and displayed as three discontinuous nucleotide fragments. After expression into RNA, the three sections can fold spontaneously into a tight core that promotes the correct folding of 
other RNA functional groups fused to the RNA sequence. Three individual fragments dispersed at any location within the sequence would allow the other RNA functional modules to fold into their authentic structures with functions, as tested using HBV ribozyme, siRNA, and aptamers of Spinach, Malachite Green (MG), and Streptavidin as model functional groups (Fig. 7). Only 9 complementary nucleotides are required for any two of the three 18-nt 3WJ components. The three 9-bp segments can override other doublestranded segments with more than 15-bp within the fusion RNA. This system enables the production of fusion RNA complexes harbouring multiple functional RNA molecules with correct folding for many potential applications in nanobiotechnology. This system has also been used to investigate the principles governing the folding of RNA molecules in vivo and in vitro. It was found that temporal production of RNA sequences during in vivo transcription caused RNA to fold into different conformations that could not be predicted with the routine principles derived from in vitro studies.

\section{Perspectives}

RNA as a biocompatible material is highly advantageous for nanotechnology due to its structural and functional attributes. RNA nanotechnology has provided a new means of fabricating varieties of RNA nanoparticles with exquisite control of size and shape along with tunable thermodynamic, chemical and mechanical properties. The RNA scaffolds can be functionalized with relative ease for RNA-based drugs such as siRNA, anti-miRNA, miRNA, riboswitch and ribozymes, and then self-assembled with high efficiency from modular building blocks and in the process, accelerate the progression of pure RNA-based drugs from the bench to the clinic. The use of different size, shape and physiochemical properties of RNA nanoparticles depends on the desired application and also on attaining optimal pharmacological profile with specific targeting, negligible off-target effects and toxicity, and optimal therapeutic efficacy.

Over the last decade, major challenges have been overcome to a large extent, particularly with regards to thermodynamic instability, chemical instability, toxicity and immunogenicity, but challenges still remain for widespread use of this promising platform in the research community: (1) RNA nanoparticles can get trapped in endosomes following receptor-mediated endocytosis, which can diminish their therapeutic efficacy to some extent. (2) User-friendly software need to be developed for designing RNA nanoparticles from simple set of building blocks for desired applications in a fairly quick time frame. RNA can fold into complex structures mediated by canonical and non-canonical base pairing, base stacking, and tertiary interactions and therefore computational methods for predicting the correct folding of RNA nanoparticles built from inter-molecular interactions are needed. Predicting kinetically trapped undesirable conformations of complex structures is a grand challenge and computational methods to balance kinetic aspects of RNA folding and thermodynamic control mediated by rigid motifs need to be developed. Exploiting the conformational dynamics of topologically equivalent motifs can lend further control of the thermodynamic and kinetic properties of the designed RNA nanoparticles. De novo design of RNA nanoparticles could perhaps offer more versatility in structure and function than what is available in nature for our desired applications and also offer the possibility of building complex RNA machineries. Furthermore, design of synthetic RNA nanostructures 
that are responsive of physiological stimuli such as protein and ligand binding and conditionally activate is largely an unexplored area. (3) RNA motif databases are relatively much smaller compared to small molecule and protein databases. Non-coding RNAs can adopt complex 3D structures that can possibly be used to build RNA nanomachines mimicking in vivo systems. As more papers in RNA biology and RNA structures are published, these novel structures need to be catalogued with available thermodynamic, kinetics and folding properties. (4) Advances in RNA chemistry are needed for large scale production of RNA strands (modified and longer than 80 bases) by chemical synthesis with high yield. (5) Following large scale synthesis, large-scale purification methods need to be developed. (6) One of the major advantages of using RNA is the feasibility of RNA nanoparticle production in vivo. While some progress has been made in this regard using the thermodynamically stable pRNA-3WJ ${ }^{11,47,86,88-90}$, endogenous production of programable functional RNA nanoparticles in mammalian cells to modulate biological pathways will be tremendous leap in synthetic biology. (7) CRISPR (Clustered Regularly Interspaced Short Palindromic repeats)- Cas9 has emerged as a versatile genome-editing technology ${ }^{91}$. RNA nanotechnology can possibly be integrated into the CRISPR tool to develop robust scaffolds for reprograming cells in an efficient manner.

\section{Acknowledgments}

The research in P.G.'s lab was supported by NIH Grants R01EB019036 and U01CA207946. The authors declare the following competing financial interest(s): P.G.'s Sylvan G. Frank Endowed Chair position in Pharmaceutics and Drug Delivery is funded by the CM Chen Foundation. P.G. is a consultant of Oxford Nanopore Technologies and Nanobio Delivery Pharmaceutical Co. Ltd. He is also the co-founder of Shenzhen P\&Z Biomedical Co. Ltd and its subsidiary P\&Z Biological Technology. F.H., F.P., Z.Z., S.G., H.H, and H.Y. work for Nanobio Delivery Pharmaceutical Company specializing in RNA Nanoparticles. The content is solely the responsibility of the authors and does not represent the official views of NIH.

\section{References}

1. Leontis NB, Lescoute A, Westhof E. The building blocks and motifs of RNA architecture. Curr Opin Struct Biol. 2006; 16:279-287. [PubMed: 16713707]

2. Leontis NB, Westhof E. Analysis of RNA motifs. Curr Opin Struct Biol. 2003; 13(3):300-308. [PubMed: 12831880]

3. Cruz JA, Westhof E. The Dynamic Landscapes of RNA Architecture. Cell. 2009; 136(4):604-609. [PubMed: 19239882]

4. Brion P, Westhof E. Hierarchy and dynamics of RNA folding. Ann Rev Biophys Biomol Struct. 1997; 26:113-137. [PubMed: 9241415]

5. Lander ES, Linton LM, Birren B, Nusbaum C, Zody MC, Baldwin J, et al. Initial sequencing and analysis of the human genome. Nature. 2001; 409(6822):860-921. [PubMed: 11237011]

6. Claverie JM. Fewer genes, more noncoding RNA. Science. 2005; 309(5740):1529-1530. [PubMed: 16141064]

7. Shu Y, Pi F, Sharma A, Rajabi M, Haque F, Shu D, Leggas M, Evers BM, Guo P. Stable RNA nanoparticles as potential new generation drugs for cancer therapy. Adv Drug Deliv Rev. 2014; 66C: 74-89.

8. Jasinski D, Haque F, Binzel DW, Guo P. Advancement of the Emerging Field of RNA Nanotechnology. ACS Nano. 2017; 11(2):1142-1164. [PubMed: 28045501]

9. Guo P. The emerging field of RNA nanotechnology. Nature Nanotechnology. 2010; 5(12):833-842.

10. Guo, P., Haque, F., editors. RNA Nanotechnology and Therapeutics. CRC Press; 2013. p. 1-593. 
11. Shu D, Shu Y, Haque F, Abdelmawla S, Guo P. Thermodynamically stable RNA three-way junctions for constructing multifuntional nanoparticles for delivery of therapeutics. Nat Nanotechnol. 2011; 6:658-667. [PubMed: 21909084]

12. Lescoute A, Westhof E. Topology of three-way junctions in folded RNAs. RNA. 2006; 12(1):8393. [PubMed: 16373494]

13. Laing C, Schlick T. Analysis of four-way junctions in RNA structures. J Mol Biol. 2009; 390(3): 547-559. [PubMed: 19445952]

14. Schroeder KT, McPhee SA, Ouellet J, Lilley DM. A structural database for k-turn motifs in RNA. RNA. 2010; 16(8):1463-1468. [PubMed: 20562215]

15. Bindewald E, Afonin K, Jaeger L, Shapiro BA. Multistrand RNA secondary structure prediction and nanostructure design including pseudoknots. ACS Nano. 2011; 5(12):9542-9551. [PubMed: 22067111]

16. Severcan I, Geary C, V E, C A, Jaeger L. Square-shaped RNA particles from different RNA folds. Nano Lett. 2009; 9:1270-1277. [PubMed: 19239258]

17. Afonin KA, Lin YP, Calkins ER, Jaeger L. Attenuation of loop-receptor interactions with pseudoknot formation. Nucleic Acids Res. 2012; 40(5):2168-2180. [PubMed: 22080507]

18. Afonin KA, Cieply DJ, Leontis NB. Specific RNA self-assembly with minimal paranemic motifs. J Am Chem Soc. 2008; 130:93-102. [PubMed: 18072767]

19. Shu Y, Haque F, Shu D, Li W, Zhu Z, Kotb M, Lyubchenko Y, Guo P. Fabrication of 14 Different RNA Nanoparticles for Specific Tumor Targeting without Accumulation in Normal Organs. RNA. 2013; 19:766-777.

20. Bindewald E, Hayes R, Yingling YG, Kasprzak W, Shapiro BA. RNAJunction: a database of RNA junctions and kissing loops for three-dimensional structural analysis and nanodesign. Nucleic Acids Res. 2008; 36:D392-D397. [PubMed: 17947325]

21. Guo P, Erickson S, Anderson D. A small viral RNA is required for in vitro packaging of bacteriophage phi29 DNA. Science. 1987; 236:690-694. [PubMed: 3107124]

22. Haque F, Shu D, Shu Y, Shlyakhtenko L, Rychahou P, Evers M, Guo P. Ultrastable synergistic tetravalent RNA nanoparticles for targeting to cancers. Nano Today. 2012; 7:245-257. [PubMed: 23024702]

23. Guo, P., Haque, F. RNA Nanotechnology and Therapeutics-Methods in Molecular Biology. Vol. 1297. New York: Human Press; 2015. p. 1-239.

24. Shu D, Li H, Shu Y, Xiong G, Carson WE, Haque F, Xu R, Guo P. Systemic delivery of antimiRNA for suppression of triple negative breast cancer utilizing RNA nanotechnology. ACS Nano. 2015; 9:9731-9740. [PubMed: 26387848]

25. Jasinski D, Khisamutdinov EF, Lyubchenko YL, Guo P. Physicochemically Tunable PolyFunctionalized RNA Square Architecture with Fluorogenic and Ribozymatic Properties. ACS Nano. 2014; 8:7620-7629. [PubMed: 24971772]

26. Khisamutdinov EF, Jasinski DL, Guo P. RNA as a boiling-resistant anionic polymer material to build robust structures with defined shape and stoichiometry. ACS Nano. 2014; 8:4771-4781. [PubMed: 24694194]

27. Sharma A, Haque F, Pi F, Shlyakhtenko L, Evers BM, Guo P. Controllable Self-assembly of RNA Dendrimers. Nanomedicine-Nanotechnology Biology and Medicine. 2015; 12:835-844.

28. Parlea L, Bindewald E, Sharan R, Bartlett N, Moriarty D, Oliver J, Afonin KA, Shapiro BA. Ring Catalog: A resource for designing self-assembling RNA nanostructures. Methods. 2016; 103:128137. [PubMed: 27090005]

29. Sarver M, Zirbel CL, Stombaugh J, Mokdad A, Leontis NB. FR3D: finding local and composite recurrent structural motifs in RNA 3D structures. Journal of Mathematical Biology. 2008; 56(1-2): 215-252. [PubMed: 17694311]

30. Bunka DH, Stockley PG. Aptamers come of age - at last. Nat Rev Microbiol. 2006; 4(8):588-596. [PubMed: 16845429]

31. Zhu H, Li J, Zhang XB, Ye M, Tan W. Nucleic acid aptamer-mediated drug delivery for targeted cancer therapy. ChemMedChem. 2015; 10(1):39-45. [PubMed: 25277749]

32. Zhou J, Bobbin ML, Burnett JC, Rossi JJ. Current progress of RNA aptamer-based therapeutics. Front Genet. 2012; 3:234. [PubMed: 23130020] 
33. Keefe AD, Pai S, Ellington A. Aptamers as therapeutics. Nat Rev Drug Discov. 2010; 9(7):537550. [PubMed: 20592747]

34. Sundaram P, Kurniawan H, Byrne ME, Wower J. Therapeutic RNA aptamers in clinical trials. Eur J Pharm Sci. 2013; 48(1-2):259-271. [PubMed: 23142634]

35. Mulhbacher J, St-Pierre P, Lafontaine DA. Therapeutic applications of ribozymes and riboswitches. Curr Opin Pharmacol. 2010; 10(5):551-556. [PubMed: 20685165]

36. Strobel SA, Cochrane JC. RNA catalysis: ribozymes, ribosomes, and riboswitches. Curr Opin Chem Biol. 2007; 11(6):636-643. [PubMed: 17981494]

37. Scott WG. Ribozymes. Curr Opin Struct Biol. 2007; 17(3):280-286. [PubMed: 17572081]

38. Tucker BJ, Breaker RR. Riboswitches as versatile gene control elements. Curr Opin Struct Biol. 2005; 15:342-348. [PubMed: 15919195]

39. Hannon GJ. RNA interference. Nature. 2002; 418:244-251. [PubMed: 12110901]

40. Pecot CV, Calin GA, Coleman RL, Lopez-Berestein G, Sood AK. RNA interference in the clinic: challenges and future directions. Nat Rev Cancer. 2011; 11(1):59-67. [PubMed: 21160526]

41. Binzel D, Shu Y, Li H, Sun M, Zhang Q, Shu D, Guo B, Guo P. Specific Delivery of MiRNA for High Efficient Inhibition of Prostate Cancer by RNA Nanotechnology. Molecular Therapy. 2016; 24:1267-1277. [PubMed: 27125502]

42. Shu Y, Cinier M, Shu D, Guo P. Assembly of multifunctional phi29 pRNA nanoparticles for specific delivery of siRNA and other therapeutics to targeted cells. Methods. 2011; 54:204-214. [PubMed: 21320601]

43. Zhang Y, Leonard M, Shu Y, Yang Y, Shu D, Guo P, Zhang X. Overcoming Tamoxifen Resistance of Human Breast Cancer by Targeted Gene Silencing Using Multifunctional pRNA Nanoparticles. ACS Nano. 2017; 11(1):335-346. [PubMed: 27966906]

44. Lee TJ, Yoo JY, Shu D, Li H, Zhang J, Yu JG, Jaime-Ramirez AC, Acunzo M, Romano G, Cui R, Sun HL, Luo Z, Old M, Kaur B, Guo P, Croce CM. RNA Nanoparticle-Based Targeted Therapy for Glioblastoma through Inhibition of Oncogenic miR-21. Mol Ther. 2017

45. Lee TJ, Haque F, Vieweger M, Yoo JY, Kaur B, Guo P, Croce CM. Functional assays for specific targeting and delivery of RNA nanoparticles to brain tumor. Methods Mol Biol. 2015; 1297:137152. [PubMed: 25896001]

46. Cui D, Zhang C, Liu B, Shu Y, Du T, Shu D, Wang K, Dai F, Liu Y, Li C, Pan F, Yang Y, Ni J, Li $\mathrm{H}$, Brand-Saberi B, Guo P. Regression of gastric cancer by systemic injection of RNA nanoparticles carrying both ligand and siRNA. Scientific reports. 2015; 5:10726. [PubMed: 26137913]

47. Binzel DW, Khisamutdinov EF, Guo P. Entropy-driven one-step formation of Phi29 pRNA 3WJ from three RNA fragments. Biochemistry. 2014; 53(14):2221-2231. [PubMed: 24694349]

48. Liu J, Guo S, Cinier M, Shlyakhtenko LS, Shu Y, Chen C, Shen G, Guo P. Fabrication of stable and RNase-resistant RNA nanoparticles active in gearing the nanomotors for viral DNA packaging. ACS Nano. 2011; 5(1):237-246. [PubMed: 21155596]

49. Xu Z, Sun Y, Weber JK, Cao Y, Wang W, Jasinski D, Guo P, Zhou R, Li J. Directional mechanical stability of Bacteriophage phi29 motor's 3WJ-pRNA: Extraordinary robustness along portal axis. Sci Adv. 2017; 3(5):e1601684. [PubMed: 28560321]

50. Zhang H, Endrizzi JA, Shu Y, Haque F, Sauter C, Shlyakhtenko LS, Lyubchenko Y, Guo P, Chi YI. Crystal Structure of 3WJ Core Revealing Divalent Ion-promoted Thermostability and Assembly of the Phi29 Hexameric Motor pRNA. RNA. 2013; 19:1226-1237. [PubMed: 23884902]

51. Huang L, Lilley DM. A quasi-cyclic RNA nano-scale molecular object constructed using kink turns. Nanoscale. 2016; 8(33):15189-15195. [PubMed: 27506301]

52. Ohno H, Kobayashi T, Kabata R, Endo K, Iwasa T, Yoshimura SH, Takeyasu K, Inoue T, Saito H. Synthetic RNA-protein complex shaped like an equilateral triangle. Nat Nanotechnol. 2011; 6(2): 116-120. [PubMed: 21240283]

53. Boerneke MA, Dibrov SM, Hermann T. Crystal-Structure-Guided Design of Self-Assembling RNA Nanotriangles. Angew Chem Int Ed Engl. 2016; 55(12):4097-4100. [PubMed: 26914842]

54. Bui MN, Brittany JM, Viard M, Satterwhite E, Martins AN, Li Z, Marriott I, Afonin KA, Khisamutdinov EF. Versatile RNA tetra-U helix linking motif as a toolkit for nucleic acid nanotechnology. Nanomedicine. 2017; 13(3):1137-1146. [PubMed: 28064006] 
55. Bindewald E, Grunewald C, Boyle B, O'Connor M, Shapiro B. A Computational strategies for the automated design of RNA nanoscale structures from building blocks using NanoTiler. Journal of Molecular Graphics \& Modelling. 2008; 27(3):299-308. [PubMed: 18838281]

56. Khisamutdinov E, Li H, Jasinski D, Chen J, Fu J, Guo P. Enhancing immunomodulation on innate immunity by shape transition among RNA triangle, square, and pentagon nanovehicles. Nucleic Acids Res. 2014; 42:9996-10004. [PubMed: 25092921]

57. Shu D, Moll WD, Deng Z, Mao C, Guo P. Bottom-up assembly of RNA arrays and superstructures as potential parts in nanotechnology. Nano Lett. 2004; 4:1717-1723. [PubMed: 21171616]

58. Zhang CL, Lee C-S, Guo P. The proximate 5' and 3' ends of the 120-base viral RNA (pRNA) are crucial for the packaging of bacteriophage f29 DNA. Virology. 1994; 201:77-85. [PubMed: 8178491]

59. Reid RJD, Bodley JW, Anderson D. Characterization of the prohead-pRNA interaction of bacteriophage phi29. J Biol Chem. 1994; 269:5157-5162. [PubMed: 8106496]

60. Zhang CL, Trottier M, Guo PX. Circularly permuted viral pRNA active and specific in the packaging of bacteriophage Phi29 DNA. Virology. 1995; 207:442-451. [PubMed: 7533964]

61. Chen C, Sheng S, Shao Z, Guo P. A dimer as a building block in assembling RNA: A hexamer that gears bacterial virus phi29 DNA-translocating machinery. J Biol Chem. 2000; 275(23):17510 17516. [PubMed: 10748150]

62. Dibrov SM, McLean J, Parsons J, Hermann T. Self-assembling RNA square. Proc Natl Acad Sci USA. 2011; 108(16):6405-6408. [PubMed: 21464284]

63. Davidovich C, Bashan A, uerbach-Nevo T, Yaggie RD, Gontarek RR, Yonath A. Induced-fit tightens pleuromutilins binding to ribosomes and remote interactions enable their selectivity. Proc Natl Acad Sci USA. 2007; 104(11):4291-4296. [PubMed: 17360517]

64. Guo P, Zhang C, Chen C, Trottier M, Garver K. Inter-RNA interaction of phage phi29 pRNA to form a hexameric complex for viral DNA transportation. Mol Cell. 1998; 2:149-155. [PubMed: 9702202]

65. Chen C, Zhang C, Guo P. Sequence requirement for hand-in-hand interaction in formation of pRNA dimers and hexamers to gear phi29 DNA translocation motor. RNA. 1999; 5:805-818. [PubMed: 10376879]

66. Shu Y, Shu D, Haque F, Guo P. Fabrication of pRNA nanoparticles to deliver therapeutic RNAs and bioactive compounds into tumor cells. Nat Protoc. 2013; 8(9):1635-1659. [PubMed: 23928498]

67. Guo S, Tschammer N, Mohammed S, Guo P. Specific delivery of therapeutic RNAs to cancer cells via the dimerization mechanism of phi29 motor pRNA. Hum Gene Ther. 2005; 16:1097-1109. [PubMed: 16149908]

68. Chworos A, Severcan I, Koyfman AY, Weinkam P, Oroudjev E, Hansma HG, Jaeger L. Building programmable jigsaw puzzles with RNA. Science. 2004; 306(5704):2068-2072. [PubMed: 15604402]

69. Afonin KA, Danilov EO, Novikova IV, Leontis NB. TokenRNA: A new type of sequence-specific, label-free fluorescent biosensor for folded RNA molecules. Chembiochem. 2008; 9:1902-1905. [PubMed: 18655086]

70. Grabow WW, Zakrevsky P, Afonin KA, Chworos A, Shapiro BA, Jaeger L. Self-Assembling RNA Nanorings Based on RNAI/II Inverse Kissing Complexes. Nano Lett. 2011; 11(2):878-887. [PubMed: 21229999]

71. Afonin KA, Kireeva M, Grabow WW, Kashlev M, Jaeger L, Shapiro BA. Co-transcriptional assembly of chemically modified RNA nanoparticles functionalized with siRNAs. Nano Lett. 2012; 12(10):5192-5195. [PubMed: 23016824]

72. Li H, Zhang K, Pi F, Guo S, Shlyakhtenko L, Chiu W, Shu D, Guo P. Controllable Self-Assembly of RNA Tetrahedrons with Precise Shape and Size for Cancer Targeting. Adv Mater. 2016; 28:7501-7507. [PubMed: 27322097]

73. Khisamutdinov EF, Jasinski DL, Li H, Zhang K, Chiu W, Guo P. Fabrication of RNA 3D Nanoprism for Loading and Protection of Small RNAs and Model Drugs. Advanced Materials. 2016; 28:100079-100087.

74. Hao C, Li X, Tian C, Jiang W, Wang G, Mao C. Construction of RNA nanocages by re-engineering the packaging RNA of Phi29 bacteriophage. Nat Commun. 2014; 5:3890. [PubMed: 24835104] 
75. Severcan I, Geary C, Chworos A, Voss N, Jacovetty E, Jaeger L. A polyhedron made of tRNAs. Nat Chem. 2010; 2(9):772-779. [PubMed: 20729899]

76. Afonin KA, Bindewald E, Yaghoubian AJ, Voss N, Jacovetty E, Shapiro BA, Jaeger L. In vitro assembly of cubic RNA-based scaffolds designed in silico. Nat Nanotechnol. 2010; 5(9):676-682. [PubMed: 20802494]

77. Halman JR, Satterwhite E, Roark B, Chandler M, Viard M, Ivanina A, Bindewald E, Kasprzak WK, Panigaj M, Bui MN, Lu JS, Miller J, Khisamutdinov EF, Shapiro BA, Dobrovolskaia MA, Afonin KA. Functionally-interdependent shape-switching nanoparticles with controllable properties. Nucleic Acids Res. 2017; 45(4):2210-2220. [PubMed: 28108656]

78. Yu JW, Liu ZY, Jiang W, Wang GS, Mao CD. De novo design of an RNA tile that self-assembles into a homo-octameric nanoprism. Nature Communications. 2015; 6:5724-5729.

79. Feng L, Li SK, Liu H, Liu CY, LaSance K, Haque F, Shu D, Guo P. Ocular delivery of pRNA nanoparticles: distribution and clearance after subconjunctival injection. Pharmaceutical Research. 2014; 31:1046-1058. [PubMed: 24297069]

80. Lee TJ, Haque F, Shu D, Yoo JY, Li H, Yokel RA, Horbinski C, Kim TH, Kim S-H, Nakano I, Kaur B, Croce CM, Guo P. RNA nanoparticles as a vector for targeted siRNA delivery into glioblastoma mouse model. Oncotarget. 2015; 6:14766-14776. [PubMed: 25885522]

81. Pi F, Zhang H, Li H, Thiviyanathan V, Gorenstein DG, Sood AK, Guo P. RNA nanoparticles harboring annexin A2 aptamer can target ovarian cancer for tumor-specific doxorubicin delivery. Nanomedicine. 2016; 13(3):1183-1193. [PubMed: 27890659]

82. Obad S, dos Santos CO, Petri A, Heidenblad M, Broom O, Ruse C, Fu C, Lindow M, Stenvang J, Straarup EM, Hansen HF, Koch T, Pappin D, Hannon GJ, Kauppinen S. Silencing of microRNA families by seed-targeting tiny LNAs. Nat Genet. 2011; 43(4):371-378. [PubMed: 21423181]

83. Afonin KA, Viard M, Koyfman AY, Martins AN, Kasprzak WK, Panigaj M, Desai R, Santhanam A, Grabow WW, Jaeger L, Heldman E, Reiser J, Chiu W, Freed EO, Shapiro BA. Multifunctional RNA nanoparticles. Nano Lett. 2014; 14(10):5662-5671. [PubMed: 25267559]

84. Ponchon L, Dardel F. Large scale expression and purification of recombinant RNA in Escherichia coli. Methods. 2011; 54:267-273. [PubMed: 21320602]

85. Ponchon L, Dardel F. Recombinant RNA technology: the tRNA scaffold. Nat Methods. 2007; 4(7): 571-576. [PubMed: 17558412]

86. Shu D, Khisamutdinov E, Zhang L, Guo P. Programmable folding of fusion RNA complex driven by the 3WJ motif of phi29 motor pRNA. Nucleic Acids Res. 2013; 42:e10. [PubMed: 24084081]

87. Jones CP, FerreDAmare AR. RNA quaternary structure and global symmetry. Trends in Biochemical Sciences. 2015; 40(4):211-220. [PubMed: 25778613]

88. Binzel DW, Khisamutdinov E, Vieweger M, Ortega J, Li J, Guo P. Mechanism of three-component collision to produce ultrastable pRNA three-way junction of Phi29 DNA-packaging motor by kinetic assessment. RNA. 2016 Nov; 22(11):1710-1718. Epub 2016 Sep 26. [PubMed: 27672132]

89. Hao Y, Kieft JS. Three-way junction conformation dictates self-association of phage packaging RNAs. RNA Biol. 2016; 13:635-45. [PubMed: 27217219]

90. Hill AC, Schroeder SJ. Thermodynamic stabilities of three-way junction nanomotifs in prohead RNA. RNA. 2017; 23:521-529. [PubMed: 28069889]

91. Charpentier E, Doudna JA. Biotechnology: Rewriting a genome. Nature. 2013; 495(7439):50-51. [PubMed: 23467164]

Wiley Interdiscip Rev RNA. Author manuscript; available in PMC 2019 January 01. 


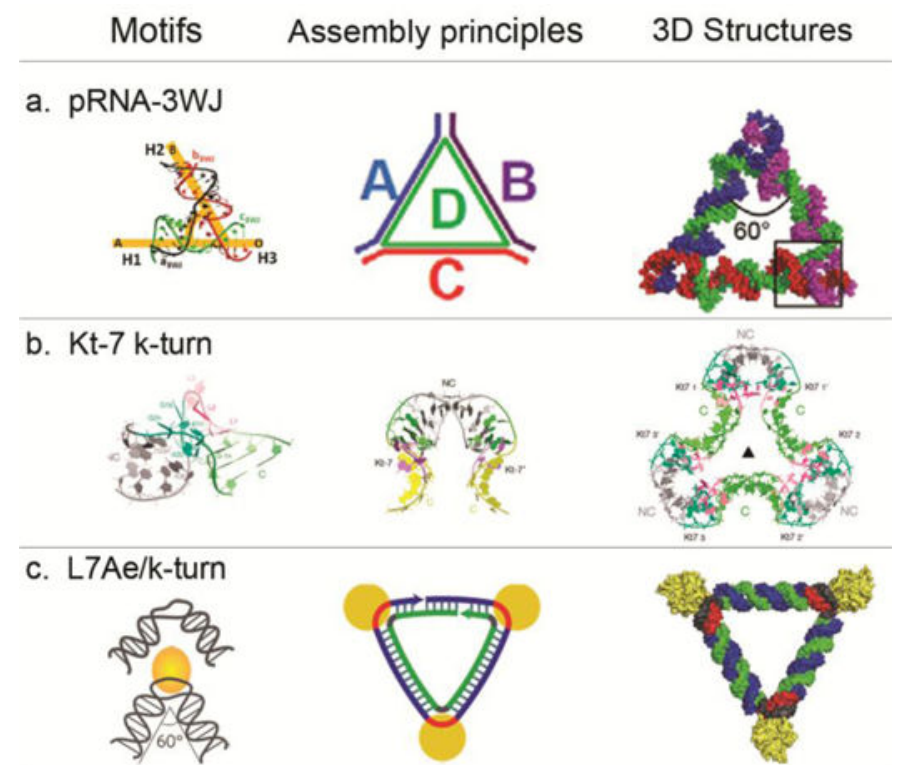

d. Ila motif

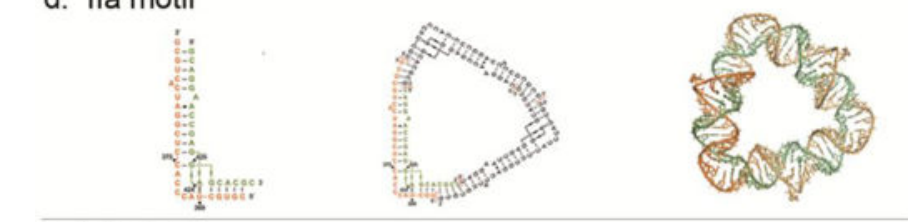

e. tetra-U

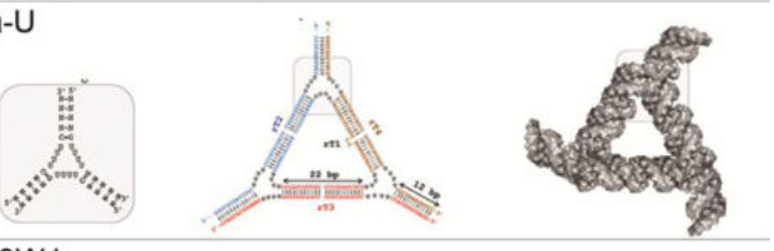

f. $16 \mathrm{~s}-3 \mathrm{WJ}$

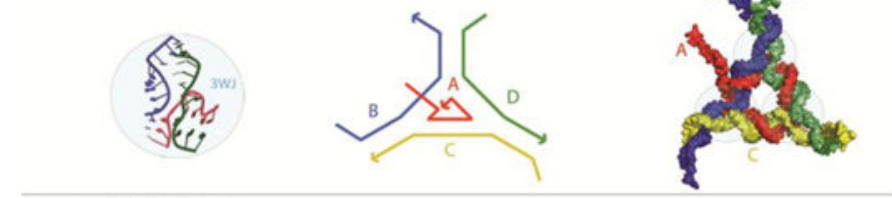

g. pRNA trimer

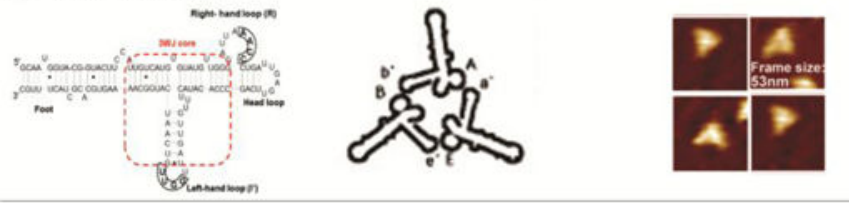

Figure 1. Design and construction of various RNA triangular nanostructures

(a) RNA nanotriangle designed and formed from four RNA oligos with pRNA-3WJ motifs at the corners ${ }^{56}$. Adapted with permission from Ref. ${ }^{56}$ (C) 2014 Oxford University Press. (b) RNA nanotriangles designed and formed from two RNA oligos with two k-turn units at each corner (PDB: 4SC1) ${ }^{51}$. Adapted with permission from Ref. ${ }^{51}$ (C) 2016 The Royal Society of Chemistry. (c) RNA-protein complex nanotriangle designed and formed utilizing the interaction of k-turn motif and L7Ae protein ${ }^{52}$. Adapted with permission from Ref. ${ }^{52}$ C 2011 Nature Publishing Group. (d) RNA nanotriangles designed and formed from four RNA 
oligos with either short or long IIa motif (PDB: 4P97, 4PHY) ${ }^{53}$. Adapted with permission from Ref. 53 @ 2016 John Wiley \& Sons, Inc. (e) RNA nanotriangle designed from three tetra-Us as building unit at the corner. Adapted with permission from Ref. ${ }^{54} \odot 2017$ Elsevier Inc. (f) RNA nanotriangle designed and formed from four RNA oligos with 3WJ motifs (PDB:11836) at the corners ${ }^{15}$. Adapted with permission from Ref. ${ }^{15}$ (c) 2011 American Chemical Society. (g) RNA triangles designed using loop-loop interactions. Three pRNA monomers A-b', B-e' and E-a' form interlocking loops to form the triangle. Adapted with permission from Ref. ${ }^{57}$ @ 2004 American Chemical Society. 


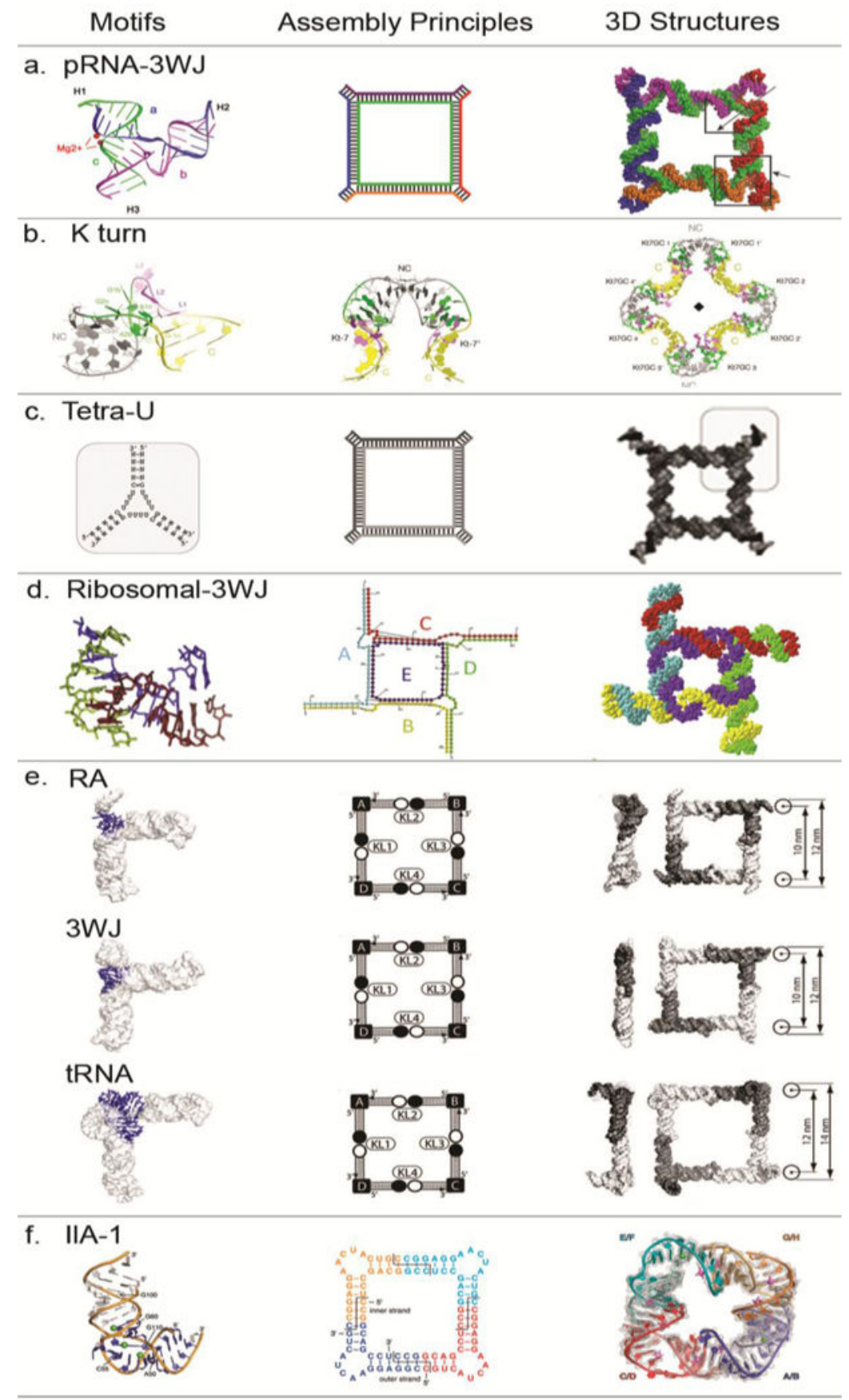

Figure 2. Design and construction of various RNA square nanostructures

(a) RNA nanosquare designed and formed from five RNA oligos with pRNA-3WJ motifs at the corners ${ }^{25}$. Adapted with permission from Ref. ${ }^{25}$ @ 2014 American Chemical Society. (b) RNA nanosquares designed and formed from two RNA oligos with two k-turn units at each corner (PDB: 4SC1) ${ }^{51}$. Adapted with permission from Ref..$^{51}$ @ 2016 The Royal Society of Chemistry. (c) RNA nanosquares designed from three-way junction formed by tetra-Us and helixes as building unit at the corner. Adapted with permission from Ref. ${ }^{54}$ @ 2017 Elsevier Inc. (d) RNA nanosquares designed and formed from five RNA oligos with $3 \mathrm{WJ}$ motifs at 
each corner(PDB, 2OGM) ${ }^{28}$. Adapted with permission from Ref. ${ }^{28} \odot 2016$ Elsevier. (e) Tectosqaure nanoparticles designed and formed from RA, $3 \mathrm{WJ}$ and tRNA motifs ${ }^{16}$. Adapted with permission from Ref. ${ }^{16}$ (C) 2009 American Chemical Society. (f) RNA nanosquare designed and formed from four piece of identical RNA oligos with IIa-1 motifs (PDB:3P59) at the corners ${ }^{62}$. Adapted with permission from Ref. ${ }^{62}$ () 2011 National Academy of Sciences. 
a.
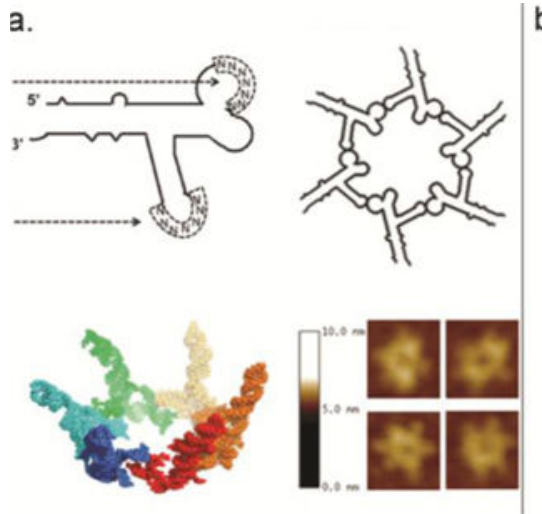

b.

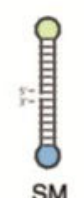

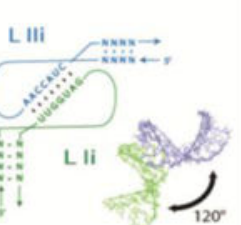

c.
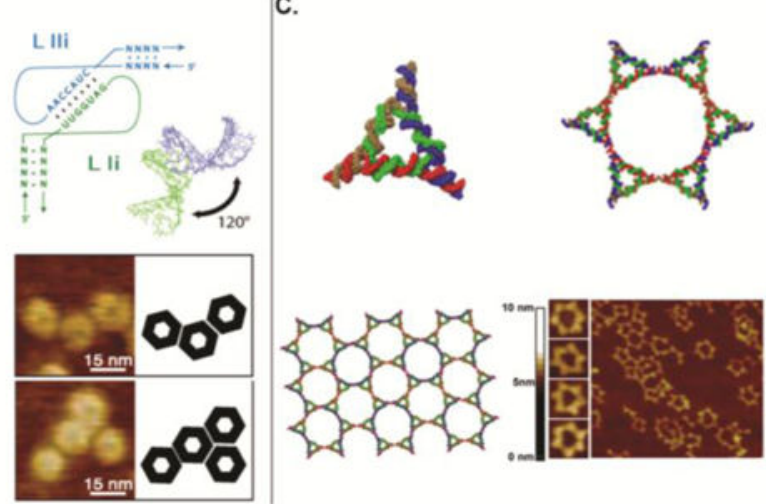

Figure 3. Design and construction of various RNA hexamer nanostructures

(a) pRNA hexamers designed and formed through intermolecular hand-in-hand interactions among 6 pieces of pRNAs ${ }^{19,21,61,64,65}$. Adapted with permission from Ref. ${ }^{19}$ ○ 2013 RNA Society. (b) RNA hexagonal nano-ring designed and formed through RNAI/II kissing complexes ${ }^{70}$. Adapted with permission from Ref. ${ }^{70}$ @ 2011 American Chemical Society. (c) RNA hexamers designed and formed through linking six triangles formed from pRNA-3WJ with helixes, constructing a supramolecular pattern resembling honeycombs. Adapted with permission from Ref. ${ }^{26}$ (c) 2014 American Chemical Society. 


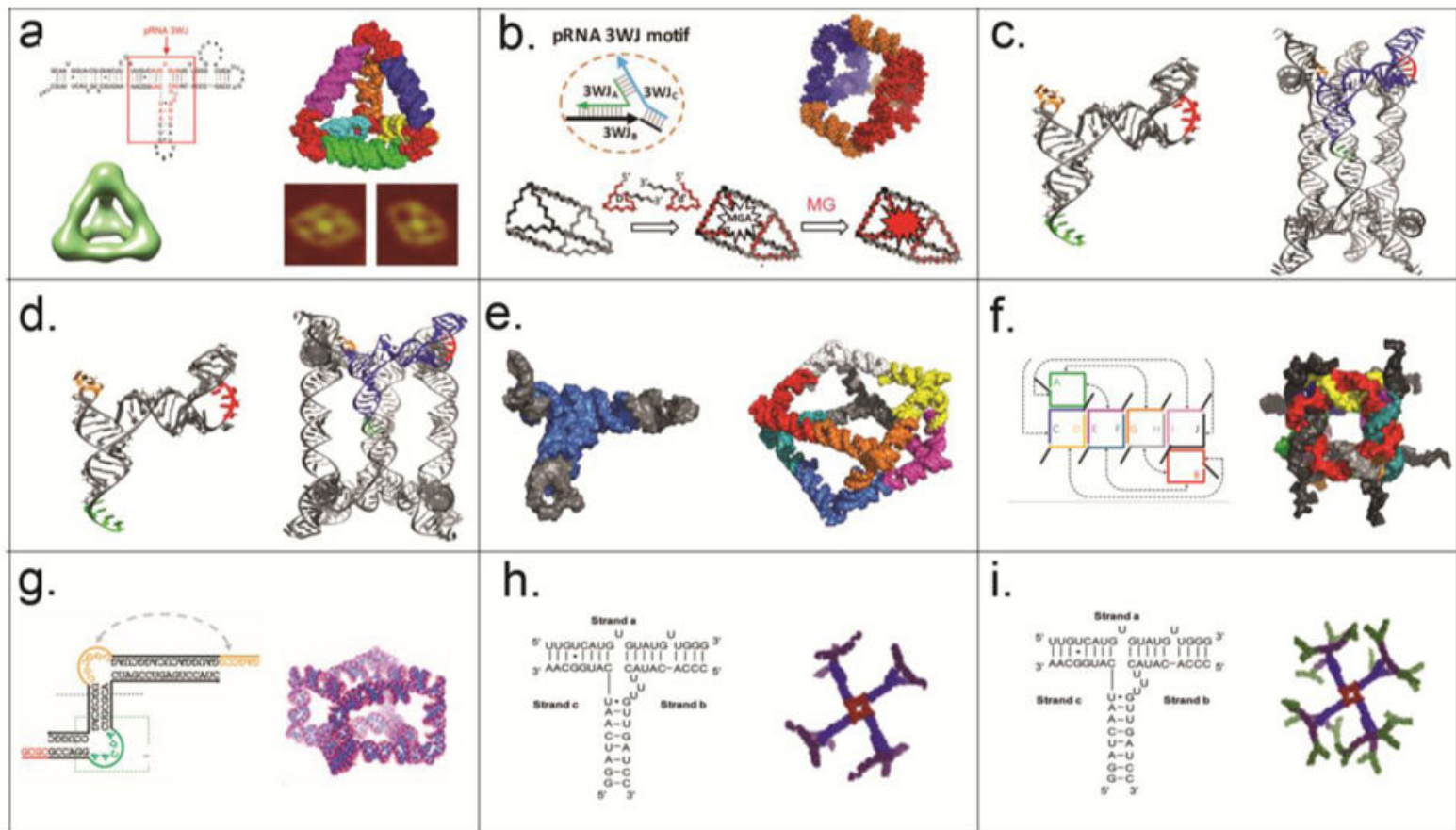

Figure 4. Design and construction of various 3D RNA nanostructures

(a) RNA tetrahedron designed and formed by placing pRNA-3WJ at the four corners ${ }^{72}$ as shown by AFM and cryo-EM. Adapted with permission from Ref. ${ }^{72}$ (C) 2016 Wiley VCH Verlag $\mathrm{GmbH}$ and Co. KGaA, Weinheim. (b) RNA prism designed and formed by placing pRNA-3WJ at the six corners ${ }^{73}$. Small RNA molecules, such as MG aptamer can be encapsulated inside the prism. Adapted with permission from Ref. ${ }^{73}$ C 2016 Wiley VCH Verlag GmbH and Co. KGaA, Weinheim. (c-d) RNA triangular nanoprism I and tetragonal nanoprism II designed and self-assembled by re-engineered pRNA ${ }^{74}$. Adapted with permission from Ref. ${ }^{74}$ (C) 2014 Macmillan Publishers Limited. (e) Polyhedron made of tRNA subunits ${ }^{75}$. Adapted with permission from Ref. ${ }^{75}$ (C) 2010 Macmillan Publishers Limited. (f) Ten stranded RNA cube with dangling ends ${ }^{76}$. Adapted with permission from Ref. $^{76}$ C 2010 Macmillan Publishers Limited. (g) Homo-octameric prism designed and formed with an RNA tile with $\mathrm{T}$ junction structure ${ }^{78}$. Adapted with permission from Ref. ${ }^{78}$ (C) 2015 Macmillan Publishers Limited. (h-i) RNA dendrimer G3 and G4 designed and formed by placing pRNA-square at the central and extended with multiple pRNA-3WJ structures $^{27}$. Adapted with permission from Ref. ${ }^{27}$ ¿ 2015 Elsevier Inc. 

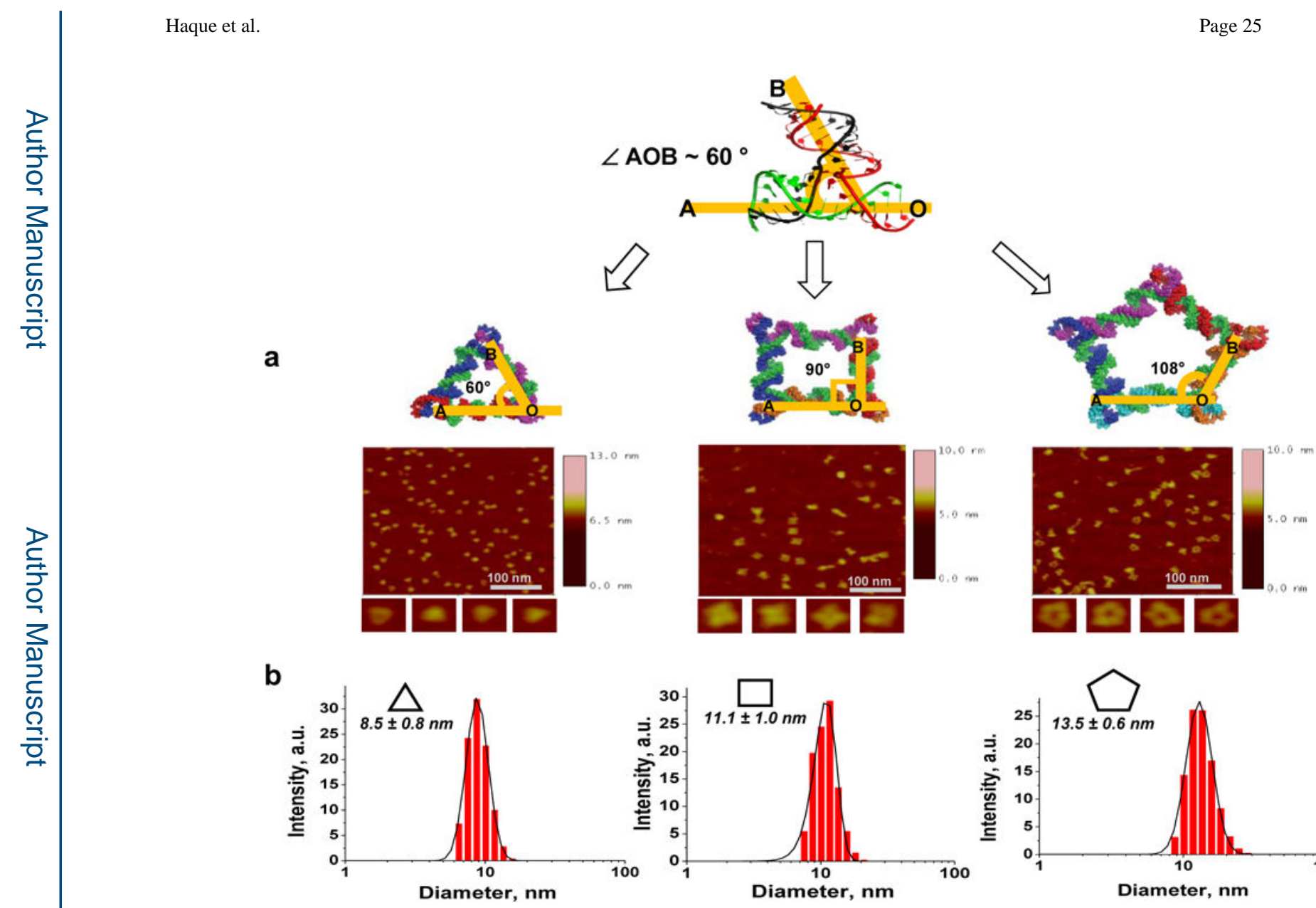

Figure 5. Design and construction of RNA triangle, square and pentagon from pRNA-3WJ motif (a) 3D model and Atomic Force Microscopy (AFM) images, and (b) Dynamic Light Scattering (DLS) assay showing the size of RNA nanoparticles ${ }^{56}$. Adapted with permission from Ref. ${ }^{56}$ C 2014 Oxford University Press 
a.
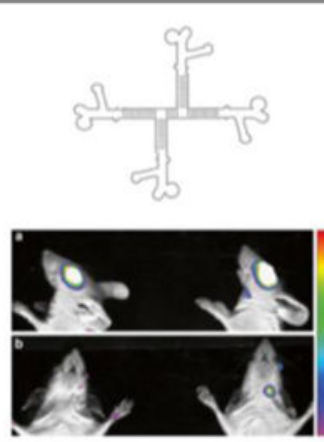

C.

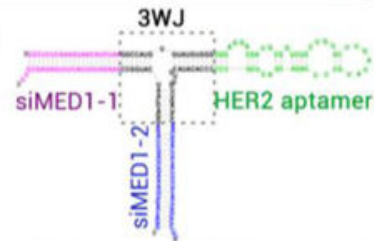

P-HER2 A647-HER2 A647-HER2

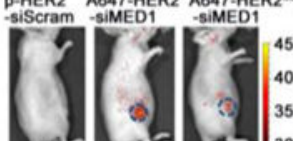

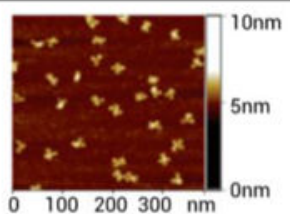

$$
\text { (1) }
$$

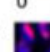

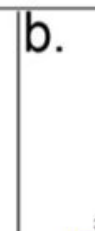
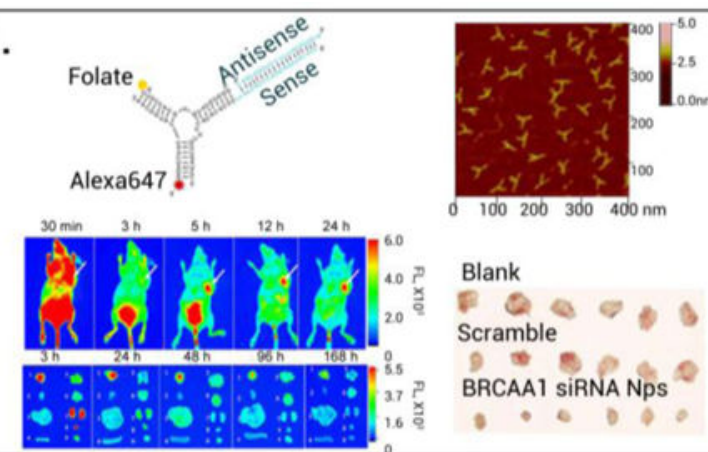

\section{Blank}

D $0 . \otimes * 0$ Scramble BRCAA1 SIRNANps 0 BRCAAI SIRNANPS

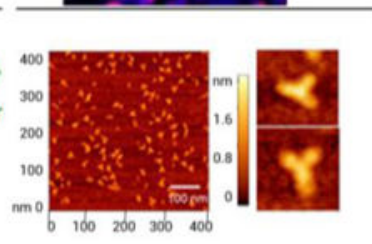

d.
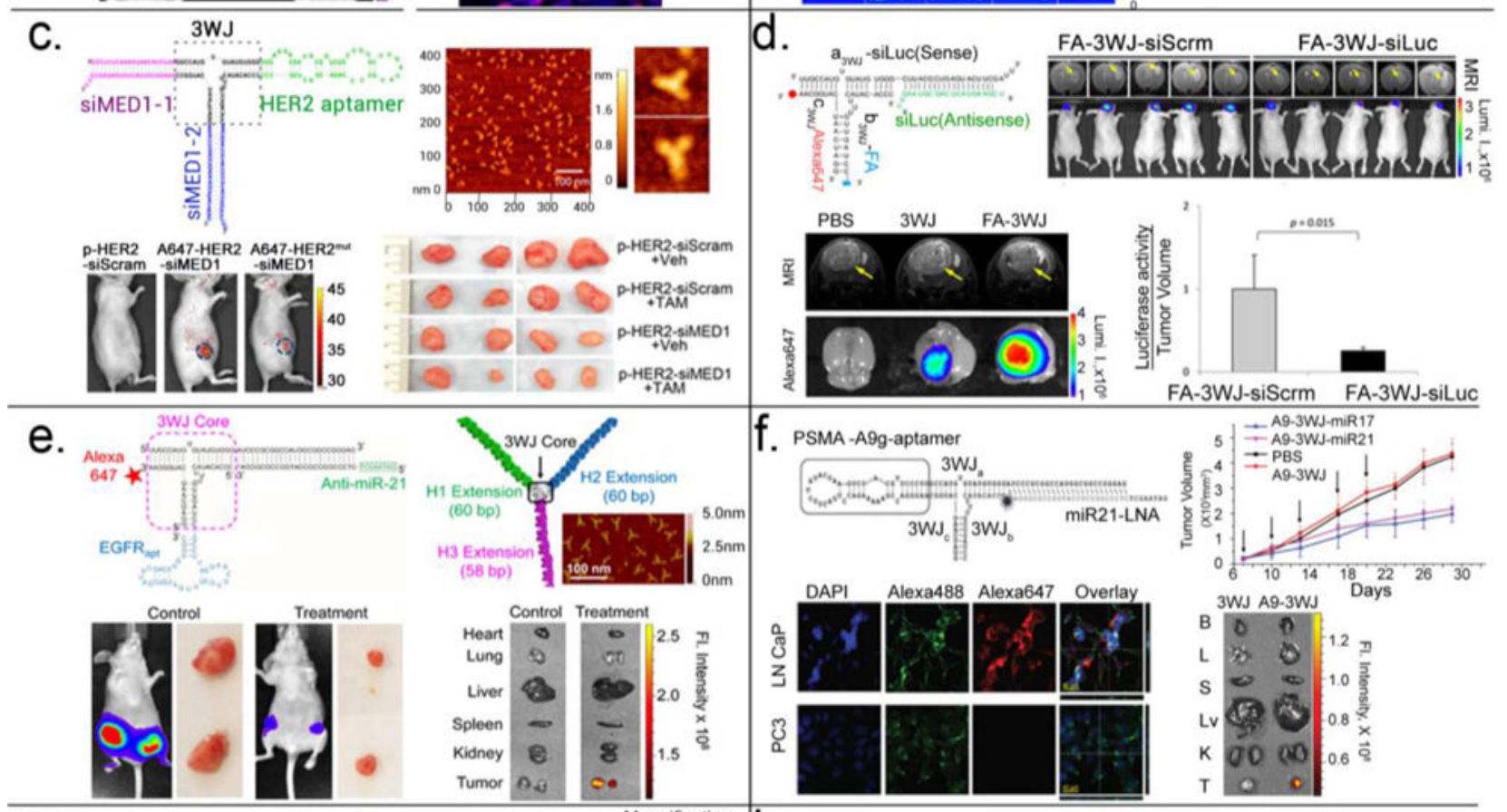

10 - 10 P.HERT:Ascram

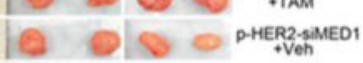

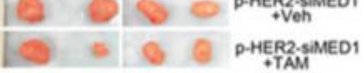
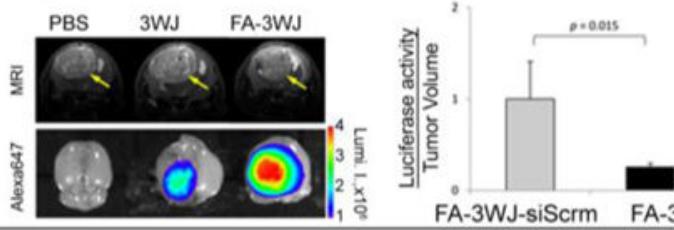

FA-3WJ-siScrm FA-3WJ-siluc

g.
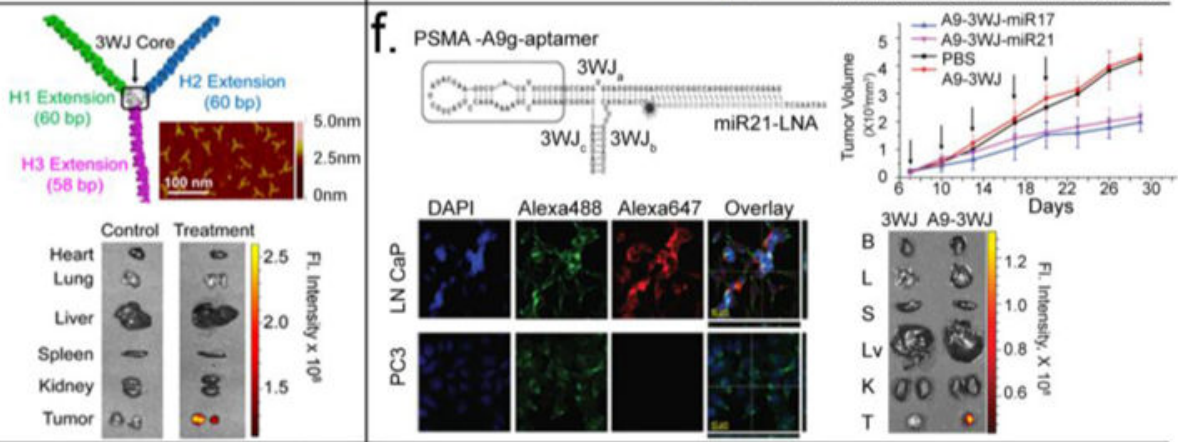

3WJ A9-3WJ

B 000.2

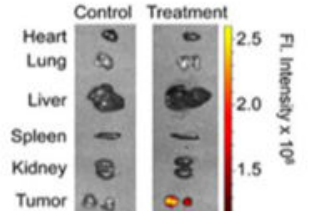

h.
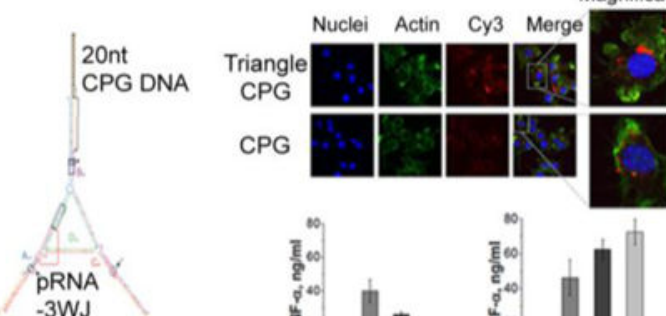

PG
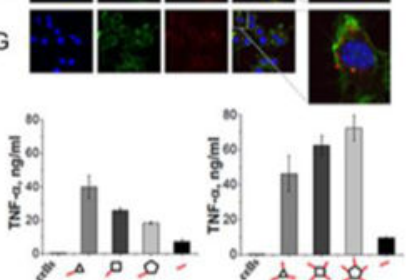

$-3 W J$
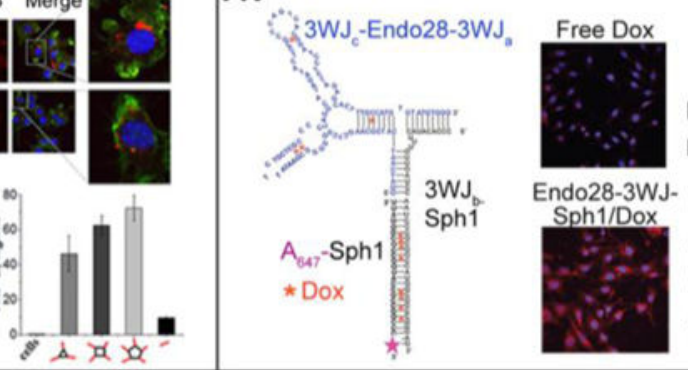

Endo28 3WJ PBS

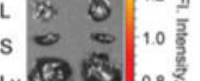

LV

K $00000 \frac{0}{0}$ $\mathrm{T} \quad$\begin{tabular}{cc|c|c|c|}
0 & 0.6 & 0
\end{tabular}

Figure 6. Application of multifunctional RNA nanoparticles in cancer research

(a) pRNA-X nanoparticle labelled with Alexa647 distributed to retinal cells after subconjunctival injection ${ }^{79}$. Adapted with permission from Ref. ${ }^{79}$ (C) 2014 Springer International Publishing Group. (b) Folate directed delivery of 3WJ-BRCAA1 siRNA to gastric cancers. Tumor inhibition observed in a gastric cancer xenograft mice model after systemic injection ${ }^{46}$. Adapted with permission from Ref. ${ }^{46}$ @ 2014 Macmillan Publishers Limited. (c) Her2 aptamer directed delivery of MED siRNA to breast cancers and effect in overcoming the tamoxifen resistance of xenograft human breast cancer ${ }^{43}$. Adapted with 
permission from Ref. ${ }^{43}$ @ 2016 American Chemical Society. (d) Folate directed delivery of $3 \mathrm{WJ}$-luciferase siRNA to glioblastoma and effect in silencing luciferase gene expression in glioblastoma mice model after systemic injection ${ }^{80}$. Adapted with permission from Ref. ${ }^{80}($ 2015 Impact Journals, LLC. (e) EGFR aptamer directed delivery of 3WJ-anti-miR21 to breast cancer cells and effect in inhibition of cancer growth in orthotopic mice model after systemic injection ${ }^{24}$. Adapted with permission from Ref. ${ }^{24}$ () 2015 American Chemical Society. (f) PSMA aptamer directed delivery of 3WJ-anti-miR21 and 3WJ-anti-miR17 to prostate cancer cells and effect in inhibition of cancer growth in mice model after systemic injection ${ }^{41}$. Adapted with permission from Ref. ${ }^{41}$ @ 2016 The American Society of Gene and Cell Therapy. (g) RNA-CpG polygons induced strong cytokine induction in vivo ${ }^{56}$. Adapted with permission from Ref. ${ }^{56}$ @ 2014 Oxford University Press. (h) Annexin A2 aptamer directed delivery of $3 \mathrm{WJ}$-doxorubicin to ovarian cancer cells, and its effect in targeting to ovarian cancer in mice model after systemic injection ${ }^{81}$. Adapted with permission from Ref. ${ }^{81} \odot 2017$ Elsevier Inc. 
a.

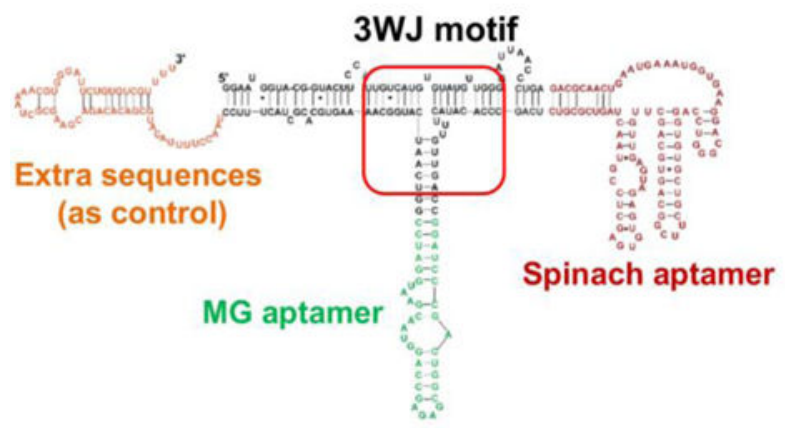

b.

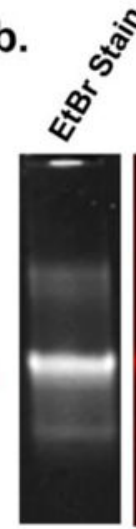

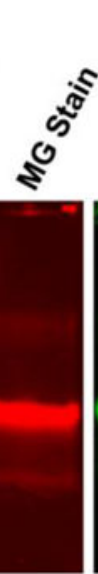

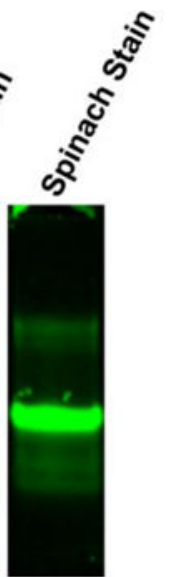

c.

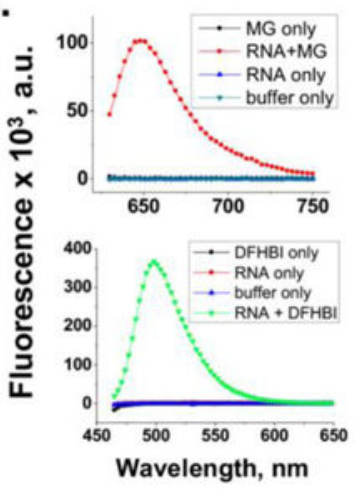

Figure 7. Functional assays of fusion RNA complexes harboring multiple functionalities expressed in vivo

(a) Construction of RNA complex harboring Malachite Green binding and Spinach aptamer. (b) $8 \%$ native PAGE verifying the fluorogenic properties of the two RNA aptamers. (c) Fluorescence spectra of MG aptamer (top) and Spinach aptamer (bottom) in solution. Figure reproduced with permission from Ref. ${ }^{86} \odot 2013$ Oxford University Press. 